J Am Chem Soc. 2018 December 19; 140(50): 17444-17455. doi:10.1021/jacs.8b06354.

\title{
Oxidative Post-Translational Modifications Accelerate Proteolytic Degradation of Calprotectin
}

\author{
Jules R. Stephan ${ }^{1}$, Fangting Yu ${ }^{1}$, Rebekah M. Costello ${ }^{1}$, Benjamin S. Bleier ${ }^{2}$, and Elizabeth \\ M. Nolan ${ }^{1, *}$ \\ ${ }^{1}$ Department of Chemistry, Massachusetts Institute of Technology, Cambridge, MA 02139, USA \\ ${ }^{2}$ Department of Otolaryngology, Massachusetts Eye and Ear Infirmary, Harvard Medical School, \\ Boston, MA
}

\begin{abstract}
Oxidative post-translational modifications affect the structure and function of many biomolecules. Herein we examine the biophysical and functional consequences of oxidative post-translational. modifications to human calprotectin (CP, S100A8/S100A9 oligomer, MRP8/MRP14 oligomer, calgranulins $\mathrm{A} / \mathrm{B}$ oligomer). This abundant metal-sequestering protein contributes to the innate immunity by starving invading microbial pathogens of transition metal nutrients in the extracellular space. It also participates in the inflammatory response. Despite many decades of study, little is known about the fate of $\mathrm{CP}$ at sites of infection and inflammation. We present compelling evidence for methionine oxidation of $\mathrm{CP}$ in vivo, supported by using ${ }^{15} \mathrm{~N}$-labeled $\mathrm{CP}$ Ser (S100A8(C42S)/S100A9(C3S)) to monitor for adventitious oxidation following human sample collection. To elucidate the biochemical and functional consequences of oxidative posttranslational modifications, we examine recombinant CP-Ser with methionine sulfoxide modifications generated by exposing the protein to hydrogen peroxide. These oxidized species coordinate transition metal ions and exert antibacterial activity. Nevertheless, oxidation of M81 in the S100A9 subunit disrupts $\mathrm{Ca}(\mathrm{II})$-induced tetramerization and, in the absence of a transition metal ion bound at the $\mathrm{His}_{6}$ site, accelerates proteolytic degradation of $\mathrm{CP}$. We demonstrate that native $\mathrm{CP}$, which contains one Cys residue in each full-length subunit, forms disulfide bonds within and between S100A8/S100A9 heterodimers when exposed to hydrogen peroxide. Remarkably, disulfide bond formation accelerates proteolytic degradation of CP. We propose a new extension to the working model for extracellular $\mathrm{CP}$ where post-translational oxidation by reactive oxygen species generated during the neutrophil oxidative burst modulates its lifetime in the extracellular space.
\end{abstract}

\section{Graphical Abstract}

*Corresponding author: lnolan@.mit.edu, Phone: 617-452-2495.

Supporting Information

Complete experimental methods, Tables S1-S9, Figures S1-S25, Supporting Discussion on AUC and oxidized protein preparation protocols. This information is available free of charge via the Internet at http://pubs.acs.org. 


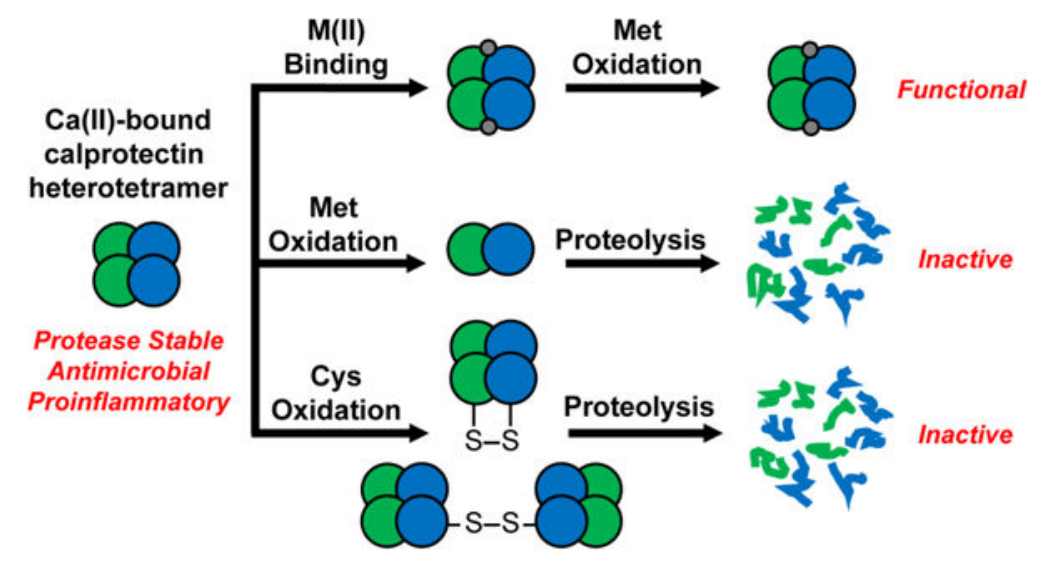

\section{Introduction}

Reactive oxygen species (ROS) are important players in the host/pathogen interaction.

Neutrophils, white blood cells that are first responders during the innate immune response, generate and release ROS at infection sites in an attempt to kill invading microbial pathogens. These reactive small molecules also have the capacity to post-translationally oxidize host biomolecules. Motivated by the need to further understand the molecular complexity of infection sites, this work examines the biophysical and functional consequences of post-translational oxidation of an abundant neutrophil protein named calprotectin (CP, S100A8/S100A9 oligomer, MRP8/MRP14 oligomer, calgranulins A/B oligomer). These studies provide a new conceptual framework for considering the speciation and lifetime of $\mathrm{CP}$ at sites of infection and inflammation, and the role of methionine sulfoxide and disulfide bonds in directing the fate of CP during the innate immune response.

$\mathrm{CP}$ is a metal-sequestering protein that contributes to the innate immune response. ${ }^{1-3}$ The protein is produced by several types of epithelial cells and white blood cells, and it is particularly abundant in neutrophils where it constitutes $\approx 40 \%$ of cytosolic protein. ${ }^{4,5}$ In the current working model, $\mathrm{CP}$ is released by neutrophils into the extracellular space at concentrations that can exceed $40 \mu \mathrm{M}(1 \mathrm{mg} / \mathrm{mL}) .{ }^{6}$ In this milieu, CP limits microbial growth by competing with invading microbes for bioavailable transition metal ions that are essential nutrients. ${ }^{1,3,7-10}$ Over the past decade, biophysical and functional studies have illuminated the molecular basis for this metal-sequestration model as described below. 7-9,11,12 Recent investigations have also probed how microbial pathogens such as Staphylococcus aureus, ${ }^{13}$ Salmonella enterica serovar Typhimurium, ${ }^{14}$ Acinetobacter baumannii, ${ }^{15}$ and Neisseria spp. ${ }^{16,17}$ adapt to metal limitation caused by CP. In contrast, to the best of our knowledge, no reports have specifically addressed what happens next for CP, either metal-free or metal-bound, in the context of this model.

In addition to its antimicrobial properties, $\mathrm{CP}$ contributes to the inflammatory response. Data suggesting that $\mathrm{CP}$ is an activator of toll-like receptor 4 (TLR4) have been reported. ${ }^{18-20}$ Moreover, murine model studies indicated that $\mathrm{CP}$-mediated proinflammatory signaling can lead to negative outcomes for the host, including promotion of lethal endotoxin-induced shock and generation of autoreactive T cells. ${ }^{18,19}$ Taken together, these studies highlight that 
$\mathrm{CP}$ is multi-functional, and suggest that $\mathrm{CP}$ can become toxic. In considering this duality, we reasoned that negative outcomes associated with CP-mediated signaling may result from a failure to clear $\mathrm{CP}$, and this line of reasoning highlighted the shortcomings of the working model in describing what happens to $\mathrm{CP}$ after release.

Previously, we approached questions of $\mathrm{CP}$ function and fate by examining the molecular basis for metal sequestration by $\mathrm{CP}$. In the apo form, $\mathrm{CP}$ exists as a 24-kDa heterodimer of S100A8 (93 amino acids, $10.8 \mathrm{kDa}$, a subunit) and S100A9 (114 amino acids, $13.2 \mathrm{kDa}, \beta$ subunit) (Figure 1). ${ }^{1,22}$ The CP heterodimer contains six different sites for coordinating cations. Each subunit contains two $\mathrm{Ca}$ (II)-binding EF-hand domains, and two binding sites for transition metal ions form at the S100A8/S100A9 interface. ${ }^{8,23}$ Site 1 is a His 3 Asp site that binds $\mathrm{Zn}$ (II) with high affinity, ${ }^{8}$ and site 2 is a $\mathrm{His}_{6}$ site that binds $\mathrm{Mn}(\mathrm{II}),{ }^{24} \mathrm{Fe}(\mathrm{II}),{ }^{10}$ $\mathrm{Ni}(\mathrm{II}),{ }^{25}$ and $\mathrm{Zn}(\mathrm{II})^{8,11}$ with high affinity (Figure 1). $\mathrm{Ca}$ (II) binding to $\mathrm{CP}$ has important structural and functional consequences. In the presence of excess $\mathrm{Ca}(\mathrm{II})$ ions, two $\mathrm{CP}$ heterodimers self-associate to form an $\alpha_{2} \beta_{2}$ heterotetramer. ${ }^{8,23,26,27}$ Conditions of high $\mathrm{Ca}$ (II) that promote heterotetramer formation also result in enhanced transition metal affinities, protease stability, and antimicrobial activity. ${ }^{8},{ }^{10},{ }^{12},{ }^{24}$ Because $\mathrm{Ca}$ (II) ion concentrations are $\approx 100 \mathrm{nM}$ in the cytoplasm of resting cells and extracellular $\mathrm{Ca}$ (II) ion concentrations are $\approx 2 \mathrm{mM},{ }^{28}$ these observations provided a working model where the heterodimer is the major cytosolic species and the $\mathrm{Ca}(\mathrm{II})$-bound heterotetramer is the major extracellular species. ${ }^{8}$ This $\mathrm{Ca}$ (II) effect allows $\mathrm{CP}$ to sequester metals and persist in the harsh extracellular space that contains host and bacterial proteases.

Over the course of our studies that addressed the biological coordination chemistry of CP, several reports identified the methionine sulfoxide (MetO) post-translational modification on the CP subunits during ex vivo analyses of human or mouse specimens by mass spectrometry. ${ }^{29-32}$ A variety of oxidants, including hydrogen peroxide $\left(\mathrm{H}_{2} \mathrm{O}_{2}\right)$, superoxide $\left(\mathrm{O}_{2}{ }^{-}\right)$, and hypochlorous acid ( $\left.\mathrm{HOCl}\right)$, are generated by the neutrophil oxidative burst. ${ }^{33}$ These oxidants can oxidize methionine sidechains to MetO. ${ }^{34-36}$ To us, these observations were intriguing and suggested an as-yet unappreciated complexity to the molecular speciation of $\mathrm{CP}$ at biological sites. The Met/MetO redox couple is often considered to serve as an antioxidant because the MetO post-translational modification can be reversed by the action of methionine sulfoxide reductases MsrA and MsrB, which are found in many cell types, including neutrophils. ${ }^{37-40}$ On the other hand, accumulation of MetO posttranslational modifications is associated with protein dysfunction. ${ }^{41}$ There are few studies on the consequences arising from MetO modification of $\mathrm{CP},{ }^{30,42}$ and we reasoned that understanding these consequences would inform the function and fate of $\mathrm{CP}$.

In this work, we identify oxidized CP species in human specimens, and we test a new hypothesis that oxidative post-translational modifications affect the function and fate of CP in the biological milieu. Our biochemical and functional results support a model where methionine oxidation and disulfide bond formation attenuate the proteolytic stability of $\mathrm{Ca}$ (II)-bound CP. In the absence of a divalent transition metal ion bound at the $\mathrm{His}_{6}$ site, oxidizing M81 of S100A9 disfavors $\mathrm{Ca}$ (II)-induced tetramerization, which leads to accelerated proteolysis by a variety of proteases. Remarkably, disulfide bonds within and between $\mathrm{CP}$ heterodimers also caused accelerated proteolysis, an effect that is particularly 
apparent when the disulfide bond includes $\mathrm{C} 42$ of S100A8. In total, these results support a new extension to the working model where extracellular CP can be oxidized by neutrophilderived ROS and subsequently degraded by proteases. We further hypothesize that accelerated degradation caused by oxidative modification serves to dampen the proinflammatory signal of $\mathrm{CP}$.

\section{Experimental Methods}

Complete experimental methods are provided as Supporting Information.

\section{Results}

\section{Oxidized CP Subunits are Observed in Human Mucus and Pus.}

Subunits of CP containing MetO have been observed in murine kidney abscesses, ${ }^{29}$ human cystic fibrosis bronchoalveolar fluid, ${ }^{30}$ human sputum from asthmatic and control subjects, 31 and human kidney stones. ${ }^{32}$ Because methionine side chains can be easily oxidized, it is often unclear whether the oxidation occurred in vivo, following sample collection, or during analysis. Nevertheless, we were intrigued by these findings and therefore sought to ascertain whether methionine oxidation of $\mathrm{CP}$ occurs in vivo and whether this post-translational modification has physiological relevance. We focused on the collection and ex vivo analyses of two types of readily available human samples, nasal mucus and pimple pus, where we expected to find CP. We selected LC-MS as an analytical method to identify unmodified and modified CP subunits. Moreover, in prior biophysical studies of CP, we overexpressed and purified ${ }^{15} \mathrm{~N}$-labeled CP-Ser (Table 1) where both subunits are globally labeled with the ${ }^{15} \mathrm{~N}$ isotope. ${ }^{21}$ We reasoned that we could use ${ }^{15} \mathrm{~N}$-labeled CP-Ser as an internal standard by adding it to human specimens immediately after collection and subsequently monitoring for whether methionine oxidation of $\mathrm{CP}$ occurs before or after sample collection. The $\mathrm{N}$ terminal Met residue of S100A9 is cleaved by the methionine aminopeptidase during overexpression in Escherichia coli; thus, full-length ${ }^{15} \mathrm{~N}-\mathrm{S} 100 \mathrm{~A} 9(\mathrm{C} 3 \mathrm{~S})$ was not observed in these experiments.

We collected and analyzed 26 nasal mucus samples from patients prior to surgery and detected both CP subunits in 15 of these samples by LC-MS (Figure 2 and S1, Table S2, Supporting Information). These analyses revealed full-length S100A8 and two truncated forms of S100A9 bearing N-terminal acetylation. Full-length S100A9 was not observed. One truncated S100A9 species lacked the initiator methionine residue and the other lacked the first five amino acids of S100A9, indicating that translation was initiated at Met5 rather than Met1 (Figure 2B,C). These truncated, N-acetylated forms of S100A9 have been previously observed in human kidney stones and bronchoalveolar fluid of cystic fibrosis patients. ${ }^{30,32}$ The longer form of S100A9 has five Met residues, the shorter form has four Met residues, and S100A8 has two Met residues. LC-MS also revealed that four of the CPcontaining mucus samples exhibited deconvoluted masses consistent with oxidized CP subunits. Although the extent of $\mathrm{CP}$ oxidation varied depending on the sample, some common species were observed (Figure 2 and S1). In two of the four samples, a population of S100A8 that bore a single additional oxygen atom ( $+16 \mathrm{Da})$ was found. All three samples contained S100A9 with at least one additional oxygen atom $(+16 \mathrm{Da})$. In three of the four 
samples, S100A9 with five additional oxygen atoms (+80 Da) was observed. One sample exhibited a series of $+16 \mathrm{Da}$ species ending with a molecule that appeared to have eight additional oxygen atoms (+128 Da) (Figure 2B). This S100A9 subunit contains five Met residues, and the locations of the three other oxygen atoms are unknown. We observed neither oxidized ${ }^{15} \mathrm{~N}-(\mathrm{S} 100 \mathrm{~A} 8) \mathrm{C} 42 \mathrm{~S}$ nor oxidized ${ }^{15} \mathrm{~N}-\mathrm{S} 100 \mathrm{~A} 9(\mathrm{C} 3 \mathrm{~S})$ in a sample that contained oxidized $\mathrm{CP}$ and ${ }^{15} \mathrm{~N}-\mathrm{CP}-\mathrm{Ser}$ (Figure 2D,E), which provided strong evidence that the oxidation in the mucus samples occurred in vivo. We note that one of the mucus samples (Figure 2E) contained a species that had a molecular weight close to that of ${ }^{15} \mathrm{~N}$ S100A9(C3S) with one additional oxygen atom; however, we were hesitant to assign it as such due to the error of $3 \mathrm{Da}$.

During the course of the mucus studies, we found that many samples were viscous and that $\mathrm{CP}$ subunits were only detected in ca. $60 \%$ of the samples. Thus, we extended the analyses to two human pus samples isolated from pimples taken from a single donor, which we found to be easier to handle than mucus. LC-MS revealed the presence of the CP subunits in the two pus samples (Figures 2 and S1). Similar to the mucus samples, we observed full-length S100A8 and truncated, N-acetylated forms of S100A9. Both pus samples also contained oxidized S100A8 and S100A9 species. The oxidized S100A8 species contained one additional oxygen atom ( $+16 \mathrm{Da}$ ) and up to five additional oxygen atoms were observed for the oxidized S100A9 species. We added ${ }^{15} \mathrm{~N}-\mathrm{CP}-\mathrm{Ser}$ to both of these pus samples with and observed no oxidized ${ }^{15} \mathrm{~N}-\mathrm{S} 100 \mathrm{~A} 8(\mathrm{C} 42 \mathrm{~S})$ species in either sample, and a small fraction of ${ }^{15} \mathrm{~N}-\mathrm{S} 100 \mathrm{~A} 9$ bearing a single additional oxygen atom $(+16 \mathrm{Da})$ was detected in in one of the two samples (Figures 2 and S1). Overall, these ex vivo studies of nasal mucus and pus provide further support for the existence of oxidized $\mathrm{CP}$ subunits in different human fluids. Importantly, the lack of oxidation of the ${ }^{15} \mathrm{~N}-\mathrm{CP}-\mathrm{Ser}$ internal standard indicates that the oxidative post-translational modifications of the $\mathrm{CP}$ subunits occurred in vivo and not during sample collection, storage, or analysis. We interpreted these data to indicate that one Met of S100A8 and up to five Met of S100A9 can be oxidized to MetO. Taken together, these observations strengthen the notion that methionine oxidation is a physiologically relevant post-translational modification of $\mathrm{CP}$.

\section{Methionine Oxidation of CP-Ser Causes Heterotetramer Dissociation.}

To investigate the consequences of methionine oxidation on the biophysical properties of $\mathrm{CP}$, we first treated the $\mathrm{Ca}$ (II)-bound CP-Ser heterotetramer with $\mathrm{H}_{2} \mathrm{O}_{2}$, an oxidant that oxidizes Cys and Met residues with high specificity, ${ }^{43}$ and monitored the reaction by analytical sizeexclusion chromatography (SEC) and LC-MS (Figure 4A,B). We chose to begin our studies with the Cys $\rightarrow$ Ser variant to avoid complications that could arise from disulfide bond formation. SEC revealed that the CP-Ser heterotetramer peak $(10.9 \mathrm{~mL}, 45.9 \mathrm{kDa})$ decreased in intensity and a new peak corresponding to the CP-Ser heterodimer $(11.5 \mathrm{~mL}, 34.9 \mathrm{kDa})$ appeared (Figure 4A). In these chromatograms, tetramer dissociation was readily apparent at the 7-h time point, and the dimer became the major species at the 23-h time point. LC-MS of the corresponding samples demonstrated that, as heterotetramers dissociated into heterodimers, the number of oxygen atoms on the CP subunits increased (Figure 4B). S100A8 had gained a single additional oxygen atom (+16 Da) within $1 \mathrm{~h}$ of incubation, and no further oxidative modification was observed until the 23 -h time point at which time 
S100A8 with two additional oxygen atoms ( $+32 \mathrm{Da}$ ) became the major species. In contrast, the extent of oxidation of S100A9 increased at each time point. Because the dissociation of the $\mathrm{Ca}$ (II)-bound heterotetramer appeared to coincide with the extent of methionine oxidation on S100A9, we reasoned that the trigger for heterotetramer dissociation was oxidation of one or more Met residues on S100A9.

In prior work, we demonstrated that coordination of $\mathrm{Mn}$ (II) or Fe(II) at the $\mathrm{His}_{6}$ site of CPSer in the absence of $\mathrm{Ca}(\mathrm{II})$ causes two heterodimers to self-associate into a heterotetramer as well as tetramerization of $\mathrm{CP}$-Ser variants harboring a I60K or I60E point mutation in S100A8 that could not tetramerize with $\mathrm{Ca}(\mathrm{II})$ alone. ${ }^{12}$ Thus, we questioned whether a $\mathrm{Ca}(\mathrm{II})$ - and transition-metal-bound heterotetramer dissociates into heterodimers upon methionine oxidation. We oxidized CP-Ser with $\mathrm{H}_{2} \mathrm{O}_{2}$ in the presence of excess $\mathrm{Ca}(\mathrm{II})$ and one equivalent of $\mathrm{Mn}(\mathrm{II})$, which only binds to the $\mathrm{His}_{6}$ site under these conditions, ${ }^{21}$ and monitored the reaction by SEC and LC-MS (Figure 4C,D). In contrast to the oxidation in the presence of only $\mathrm{Ca}(\mathrm{II})$, a peak with a maximum elution volume consistent with the heterotetramer $(11.0 \mathrm{~mL}, 43.8 \mathrm{kDa})$ was only observed, indicating that the $\mathrm{Ca}(\mathrm{II})$-and $\mathrm{Mn}(\mathrm{II})$-bound protein remained a heterotetramer over the 23-h time course. As has been observed previously, coordination of a transition metal ion at the $\mathrm{His}_{6}$ site of $\mathrm{CP}$ increases the SEC elution volume and thus decreases the apparent molecular weight of the heterotetramer compared to the $\mathrm{Ca}$ (II)-only complex..$^{8,10,24,25}$ We attribute this difference to decreased flexibility of the S100A9 C-terminal tail resulting from M(II) coordination at the His $_{6}$ site. Analysis of samples by LC-MS revealed that both subunits were oxidized in the presence of $\mathrm{Ca}(\mathrm{II})$ and $\mathrm{Mn}(\mathrm{II})$ at a rate that appeared comparable to that observed for the $\mathrm{Ca}$ (II)-only sample. These data indicate that coordination of both $\mathrm{Ca}$ (II) and $\mathrm{Mn}$ (II) stabilizes the heterotetramer, and that $\mathrm{Mn}$ (II) chelation at the $\mathrm{His}_{6}$ site does not protect Met residues from oxidation by $\mathrm{H}_{2} \mathrm{O}_{2}$.

\section{Oxidation of Met81 in S100A9 Serves as the Determinant for Heterotetramer Dissociation.}

In order to better understand the molecular basis of $\mathrm{H}_{2} \mathrm{O}_{2}$-induced dissociation of the $\mathrm{Ca}$ (II)bound CP-Ser heterotetramer, we investigated the contributions of individual S100A9 Met residues to this process. We overexpressed and purified three new CP-Ser variants that each contain a single Met $\rightarrow$ Ala mutation at position 63, 81, or 83 of S100A9(C3S). M63 of S100A9 is close to the C-terminal EF-hand, M81 of S100A9 appears to participate in the dimer-dimer interface, and M83 of S100A9 is close to the dimer-dimer interface (Figure S2). These variants were obtained as pure heterodimers (Table S3, Figure S4). Circular dichroism (CD) spectroscopy in the absence and presence of $\mathrm{Ca}$ (II) demonstrated that the a-helicity of the proteins was not perturbed by the mutations (Figure S5). SEC performed in the presence of $\mathrm{Ca}$ (II) indicated that all three $\mathrm{Ca}$ (II)-bound $\mathrm{CP}$-Ser variants eluted as tetramers (Figure 5); therefore, the Met $\rightarrow$ Ala mutations in S100A9(C3S) did not perturb Ca(II)-induced tetramerization, at least as ascertained by this technique. In contrast, SEC revealed that treatment of the Met $\rightarrow$ Ala variants with $\mathrm{H}_{2} \mathrm{O}_{2}$ in the presence of $\mathrm{Ca}$ (II) caused the $\mathrm{M} 63 \mathrm{~A}$ and $\mathrm{M} 83 \mathrm{~A}$ variants to dissociate into dimers, whereas the $\mathrm{M} 81 \mathrm{~A}$ variant remained a tetramer (Figure 5). LC-MS of the Met $\rightarrow$ Ala variants after $\mathrm{H}_{2} \mathrm{O}_{2}$ treatment displayed oxidation comparable to CP-Ser (Figure S6). These results show that $\mathrm{H}_{2} \mathrm{O}_{2}$-induced dissociation of the $\mathrm{Ca}$ (II)-bound heterotetramer is dependent on oxidizing M81 of S100A9; however, these data 
do not inform whether oxidation of one or both M81 residues in the heterotetramer is required to initiate dissociation.

Preparation of Oxidized CP-Ser.

In order to further study CP-Ser bearing MetO modifications, we optimized a protocol to obtain milligram quantities of oxidized CP-Ser (Supporting Discussion, Figure S3). By incubating crude CP-Ser with $\mathrm{H}_{2} \mathrm{O}_{2}$, we identified conditions that provided either CP-Ser $\mathrm{O}_{4}$, oxidized CP-Ser predominantly comprised of S100A8 with one additional oxygen atom and S100A9 with three additional oxygen atoms, or CP-Ser $\mathrm{O}_{5}$, predominantly oxidized CPSer comprised of S100A8 with one additional oxygen atom and S100A9 with four additional oxygen atoms (Table $\mathrm{S} 3$ and Figure S7). Analysis of CP-Ser $\mathrm{O}_{4}$ and CP-Ser $\mathrm{O}_{5}$ by $\mathrm{CD}$ spectroscopy in the absence and presence of excess $\mathrm{Ca}(\mathrm{II})$ ions revealed that the a-helicity of the CP scaffold was unaffected by methionine oxidation (Figure S4).

\section{CP-Ser $\mathrm{O}_{4}$ and $\mathrm{CP}$-Ser $\mathrm{O}_{5}$ Exhibit Defective $\mathrm{Ca}$ (II)-Induced Tetramerization.}

To further examine the consequences of methionine oxidation on the biophysical properties of $\mathrm{CP}$, we investigated the oligomeric states of CP-Ser $\mathrm{O}_{4}$ and CP-Ser $\mathrm{O}_{5}$. We first examined the proteins by using analytical SEC to determine if they recapitulated the tetramerizationdeficient behavior that occurred after treating $\mathrm{CP}$-Ser with $\mathrm{H}_{2} \mathrm{O}_{2}$ (Figure 6A). In the absence of added metal ions, $\mathrm{CP}$-Ser $\mathrm{O}_{4}$ and $\mathrm{CP}$-Ser $\mathrm{O}_{5}$ each had an elution volume of $\approx 11.6 \mathrm{~mL}$ $(33.4 \mathrm{kDa})$, consistent with the apo heterodimer (Figure 6A). In the presence of excess $\mathrm{Ca}(\mathrm{II})$ ions, the $\mathrm{CP}-\mathrm{Ser} \mathrm{O}_{4}$ and $\mathrm{CP}-\mathrm{Ser} \mathrm{O}_{5}$ peaks maintained a maximum peak height consistent with the heterodimer elution volume. However, the peaks broadened, suggesting that both dimeric and tetrameric species exist under these high-Ca(II) conditions (Figure 6A). When $\mathrm{Mn}$ (II) (Figure S8) or both $\mathrm{Ca}(\mathrm{II})$ and $\mathrm{Mn}$ (II) (Figure 6A) were present, CP-Ser $\mathrm{O}_{4}$ and CP-Ser $\mathrm{O}_{5}$ tetramerized. Thus, the SEC experiments with CP-Ser $\mathrm{O}_{4}$ and CP-Ser $\mathrm{O}_{5}$ demonstrated that the proteins displayed oligomeric properties consistent with $\mathrm{H}_{2} \mathrm{O}_{2}$-treated $\mathrm{CP}-\mathrm{Ser}$, and would be useful for further studying the effects of Met oxidation on CP-Ser.

Anion exchange chromatography allows separation of CP-Ser heterodimers from S100A9(C3S) homodimers, and we employed this technique to ascertain whether Met oxidation caused conversion of the S100A8/S100A9 heterodimer to the S100A8 and S100A9 homodimers (Figure S9). We attempted to include the S100A8(C42S) homodimer in this analysis; however, its peak profile and retention time were highly variable between runs. The chromatograms for CP-Ser, CP-Ser $\mathrm{O}_{4}$, and $\mathrm{CP}-\mathrm{Ser} \mathrm{O}_{5}$ each revealed a single peak with an elution volume of $29.3 \mathrm{~mL}$ consistent with the S100A8(C42S)/S100A9(C3S) heterodimer, and no peak corresponding to the S100A9(C3S) homodimer $(37.2 \mathrm{~mL})$ was observed. Thus, we concluded that methionine oxidation does not cause $\mathrm{CP}$ heterooligomers to convert into S100A8 and S100A9 homodimers.

\section{CP-Ser $\mathrm{O}_{4}$ and $\mathrm{CP}-S e r \mathrm{O}_{5}$ Interconvert Between Heterodimers and Heterotetramers.}

To further elucidate the oligomerization behavior of CP-Ser $\mathrm{O}_{4}$ and CP-Ser $\mathrm{O}_{5}$ in the presence of excess $\mathrm{Ca}$ (II) ions, we employed velocity analytical ultracentrifugation (AUC), a powerful technique for studying protein oligomerization that is capable of differentiating between interacting and non-interacting systems (Supporting Discussion). ${ }^{44,45}$ Along these 
lines, two scenarios that would give rise to the observed SEC peak shapes for CP-Ser $\mathrm{O}_{4}$ and CP-Ser $\mathrm{O}_{5}$ can be considered: (i) the oxidized proteins containing a population of tetramers and a population of dimers that do not interconvert or (ii) the oxidized proteins are in a dynamic equilibrium between heterodimer and heterotetramer.

We repeated an earlier AUC analysis of CP-Ser in the absence and presence of excess $\mathrm{Ca}$ (II) ions, and we used SEDFIT to obtain peak profiles and $\mathrm{S}$ values in good agreement with our prior data for the apo heterodimer $\left(s_{2 O, W}=2.2 \mathrm{~S}\right)$ and the $\mathrm{Ca}(\mathrm{II})$-bound heterotetramer $\left(s_{20, W}\right.$ $=3.7 \mathrm{~S}$ ) (Figures $6 \mathrm{~B}$ and S10 and Table S4). ${ }^{12}$ We also examined two independent preparations of $\mathrm{CP}-\mathrm{Ser} \mathrm{O}_{4}$ and $\mathrm{CP}-\mathrm{Ser} \mathrm{O}_{5}$. In the absence of $\mathrm{Ca}(\mathrm{II})$ ions, the sedimentation profiles of CP-Ser $\mathrm{O}_{4}$ and CP-Ser $\mathrm{O}_{5}$ were indistinguishable from that of CP-Ser (Figures $6 \mathrm{~B}$ and $\mathrm{S} 10$ ), which was consistent with the $\mathrm{AXC}$ and SEC studies. In the presence of $\mathrm{Ca}(\mathrm{II})$ ions, the sedimentation profiles of CP-Ser $\mathrm{O}_{4}$ and $\mathrm{CP}-\mathrm{Ser} \mathrm{O}_{5}$ displayed the hallmarks of dynamically interconverting systems (Figures 6B and S10). In particular, the peaks in the sedimentation profiles broadened, in some cases to the point where the heterodimer and heterotetramer peaks could not be resolved. Accordingly, the calculated S values for the observed peaks were in between those of the heterodimer and heterotetramer. In the profiles shown here (Figure 6B), CP-Ser $\mathrm{O}_{4}(+\mathrm{Ca}(\mathrm{II}))$ displayed two broad peaks with $\mathrm{S}$ values between the dimer and tetramer $\left(s_{20, W}=2.5 \mathrm{~S}\right.$ and $\left.3.5 \mathrm{~S}\right)$, and $\mathrm{CP}-\mathrm{Ser} \mathrm{O}_{5}$ exhibited a single broad peak $\left(s_{20, W}=3.3 \mathrm{~S}\right)$. We also analyzed the AUC data using DCDT,$+{ }^{46,47}$ which yielded results consistent with the SEDFIT analyses (Table S5 and Figure S11). Taken together, we concluded that Met oxidation of CP-Ser does not fully prevent $\mathrm{Ca}$ (II)-induced tetramerization. Rather, the heterodimer-heterodimer equilibrium is strongly shifted to the heterodimer in the presence of excess $\mathrm{Ca}(\mathrm{II})$ ions.

\section{CP-Ser Retains Antimicrobial Activity after Methionine Oxidation.}

To evaluate the effect of methionine oxidation on the antimicrobial activity (AMA) of CP, we performed AMA assays against Escherichia coli ATCC 25922 and Staphylococcus aureus ATCC 25923 using CP-Ser, CP-Ser $\mathrm{O}_{4}$ and CP-Ser $\mathrm{O}_{5}$ (Figure S12). The assays were performed in Tris:TSB medium supplemented with $2 \mathrm{mM} \mathrm{Ca(II)} \mathrm{to} \mathrm{mimic} \mathrm{the} \mathrm{extracellular}$ $\mathrm{Ca}$ (II) concentration. Under these growth conditions, CP-Ser and the oxidized species displayed concentration-dependent growth inhibition of both bacterial species. A comparison of CP-Ser to CP-Ser $\mathrm{O}_{4}$ and $\mathrm{CP}-\mathrm{Ser}_{5} \mathrm{O}_{5}$ indicates that methionine oxidation caused some attenuation of antibacterial activity. For E. coli, this trend is most evident at 250 $\mu \mathrm{g} / \mathrm{mL}$ of protein where CP-Ser completely inhibited growth and CP-Ser $\mathrm{O}_{4}$ and CP-Ser $\mathrm{O}_{5}$ inhibited growth to a lesser degree. For $S$. aureus, CP-Ser $\mathrm{O}_{4}$ and $\mathrm{O}_{5}$ were less active than $\mathrm{CP}-\mathrm{Ser}$ at 250 and $500 \mu \mathrm{g} / \mathrm{mL}$. Nevertheless, ex vivo analyses of human fluids has indicated that $\mathrm{CP}$ concentrations can reach $>1 \mathrm{mg} / \mathrm{mL}$ at infection sites, ${ }^{6}$ and both $\mathrm{CP}-\mathrm{Ser} \mathrm{O}_{4}$ and $\mathrm{O}_{5}$ fully inhibit bacterial growth at these concentrations. We note that our finding that methionine oxidation does not markedly attenuate the activity of $\mathrm{CP}$ refutes conclusions from prior work where oxidation of (A8)M1 was reported to abolish the antimicrobial activity of $\mathrm{CP}^{30}$ This study used $\mathrm{HOCl}$ as the oxidant, and other Met and non-Met residues were also reported to be oxidized in these reactions. Thus, we reason that the further oxidation of the protein scaffold was responsible for the observed loss of antibacterial activity following $\mathrm{HOCl}$ treatment. 


\section{Oxidized CP-Ser Binds Transition Metals with High Affinity.}

To provide an initial evaluation of the metal-withholding capabilities of oxidized CP-Ser, we compared the abilities of CP-Ser, CP-Ser $\mathrm{O}_{4}$, and CP-Ser $\mathrm{O}_{5}$ to compete with the $\mathrm{Ca}$ (II)insensitive fluorescent metal-ion sensor Zinpyr-1 (ZP1 $)^{48}$ for $\mathrm{Mn}(\mathrm{II}), \mathrm{Fe}(\mathrm{II}), \mathrm{Ni}(\mathrm{II})$, and $\mathrm{Zn}$ (II) (Figure S13). Under conditions of excess Ca(II) ions, CP-Ser, CP-Ser $\mathrm{O}_{4}$ and CP-Ser $\mathrm{O}_{5}$ outcompeted $\mathrm{ZP} 1$ for these four transition metal ions. Although these results do not rule out the possibility that methionine oxidation perturbs the binding affinities of $\mathrm{CP}$ for transition metal ions, these results demonstrate that, in the presence of excess $\mathrm{Ca}(\mathrm{II}), \mathrm{CP}-\mathrm{Ser}$ $\mathrm{O}_{4}$ and $\mathrm{CP}-\mathrm{Ser} \mathrm{O}_{5}$ coordinate transition metals with sufficiently high affinity to outcompete ZP1. The ability of CP-Ser $\mathrm{O}_{4}$ and CP-Ser $\mathrm{O}_{5}$ to chelate transition metals with high affinity is consistent with the observed growth inhibitory activity (Figure S12).

\section{Oxidized CP-Ser is Protease Sensitive.}

In prior work, we observed that two $\mathrm{Ca}$ (II)-bound tetramer-deficient variants of $\mathrm{CP}$-Ser that do not form heterotetramers in the presence of excess $\mathrm{Ca}$ (II) were more easily degraded by host proteases than $\mathrm{Ca}(\mathrm{II})$-bound $\mathrm{CP}-\mathrm{Ser} .{ }^{12}$ We therefore questioned whether methionine oxidation enhances the protease susceptibility of CP-Ser and performed protease digestion assays with $\mathrm{CP}$-Ser, $\mathrm{CP}-\mathrm{Ser} \mathrm{O}_{4}$, and $\mathrm{CP}-\mathrm{Ser} \mathrm{O}_{5}$ using trypsin, chymotrypsin, human neutrophil elastase (HNE), and proteinase $\mathrm{K}$. These assays were performed in the presence of excess $\mathrm{Ca}(\mathrm{II})$ or in the presence of both excess $\mathrm{Ca}$ (II) and one equivalent of $\mathrm{Mn}$ (II) (Figure 7 and S14-S17). The reactions were analyzed by HPLC using a gradient that separated S100A8 (37.9 min), S100A9 (39.4 min), S100A8+O (37.3 min), S100A9+3O (37.8 $\mathrm{min})$, and $\mathrm{S} 100 \mathrm{~A} 9+4 \mathrm{O}$ (36.1 $\mathrm{min})$. With this gradient, doubling of the oxidized S100A9 peaks occurred. Although the precise origin of the peak doubling is unknown, the phenomenon may arise from a mixture of MetO diastereomers and/or MetO regioisomers.

In agreement with our prior work, ${ }^{12}$ inhibiting $\mathrm{Ca}$ (II)-induced tetramerization resulted in accelerated proteolysis of CP-Ser (Figure 7 and S14-S17, and Supporting Discussion). For instance, in the presence of trypsin and excess $\mathrm{Ca}(\mathrm{II})$, we did not observe cleavage of CPSer, whereas CP-Ser $\mathrm{O}_{4}$ and $\mathrm{CP}-\mathrm{Ser} \mathrm{O}_{5}$ were nearly quantitatively degraded after $3 \mathrm{~h}$ (Figure 7A). In the presence of chymotrypsin and $\mathrm{Ca}$ (II) ions, CP-Ser exhibited slow cleavage of the $\mathrm{S} 100 \mathrm{~A} 9$ tail whereas $\mathrm{CP}-\mathrm{Ser} \mathrm{O}_{4}$ and $\mathrm{CP}-\mathrm{Ser}_{5}$ were cleaved to peptides (Figure S14). Although all of the proteases displayed greater activity against CP-Ser $\mathrm{O}_{4}$ and CP-Ser $\mathrm{O}_{5}$ than $\mathrm{CP}-\mathrm{Ser}$ in the presence of $\mathrm{Ca}$ (II), HNE degraded the oxidized proteins much more slowly than the other proteases (Figure S15). Additionally, HNE was the only protease for which we observed a marked difference in the degradation rate between $\mathrm{S} 100 \mathrm{~A} 9+3 \mathrm{O}$ and S100A9+4O (Figures S15 and S16). When we performed the same experiments in the presence of 1 eq. $\mathrm{Mn}(\mathrm{II})$, we observed no degradation of CP-Ser, CP-Ser $\mathrm{O}_{4}$, or CP-Ser $\mathrm{O}_{5}$ (Figure 7B and Figures S14-S17). To ascertain whether this effect was Mn(II)-specific or a general consequence of having a divalent metal ion coordinated at the $\mathrm{His}_{6}$ site, we treated CP-Ser, CP-Ser $\mathrm{O}_{4}$, and CP-Ser $\mathrm{O}_{5}$ with trypsin in the presence of excess $\mathrm{Ca}(\mathrm{II})$ and 1 eq. $\mathrm{Fe}(\mathrm{II})$ under anaerobic conditions. The Fe(II)-bound protein was also protected from degradation (Figure S18). Based on our prior studies of $\mathrm{Mn}$ (II)- and $\mathrm{Fe}(\mathrm{II})$-induced tetramerization of CP-Ser and variants, ${ }^{12}$ and the current work showing that $\mathrm{CP}-\mathrm{Ser} \mathrm{O}_{4}$ and $\mathrm{CP}-\mathrm{Ser} \mathrm{O}_{5}$ form tetramers in the presence of $\mathrm{Ca}$ (II) and 1 eq. $\mathrm{Mn}$ (II) (Figure 6), we attribute 
the recovery of protease stability observed for $\mathrm{Mn}(\mathrm{II})$ - and $\mathrm{Fe}(\mathrm{II})$-bound oxidized $\mathrm{CP}$ species to transition-metal-induced tetramerization.

\section{Oxidation of CP Yields Disulfide-Linked Oligomers.}

$\mathrm{CP}$ contains two Cys residues at position 42 of S100A8 and position 3 of S100A9. Similar to methionine, Cys residues are susceptible to oxidation by $\mathrm{H}_{2} \mathrm{O}_{2} \cdot{ }^{43}$ Thus, our studies with CPSer did not take the possibility of $\mathrm{H}_{2} \mathrm{O}_{2}$-mediated oxidation of $\mathrm{C} 42$ of $\mathrm{S} 100 \mathrm{~A} 8$ or $\mathrm{C} 3$ of S100A9 into account. With an understanding of the consequences of methionine oxidation for CP-Ser in hand, we shifted our focus to studying the more complex Cys-containing protein.

We began by examining whether treating $\mathrm{CP}$ with $100 \mu \mathrm{M} \mathrm{H}_{2} \mathrm{O}_{2}$ resulted in disulfide-bond formation in the absence or presence of excess $\mathrm{Ca}$ (II) ions by non-reducing SDS-PAGE and western blot (Figure 8A). Under our conditions, we observed minimal formation of disulfide bonds when $\mathrm{CP}$ was incubated without $\mathrm{H}_{2} \mathrm{O}_{2}$ (Figure $8 \mathrm{~A}$ ). In the absence of $\mathrm{Ca}(\mathrm{II})$, we observed bands consistent with disulfide-linked S100A8-S100A9 and S100A9-S100A9 species at the 1-h time point (Figure 8A). We also observed a weak band assigned to a disulfide-linked S100A8-S100A8 species appeared at $7 \mathrm{~h}$ and $23 \mathrm{~h}$. In the presence of excess $\mathrm{Ca}(\mathrm{II})$, the disulfide reactivity changed. At the 1-h time point, the S100A9-S100A9 species was dominant and negligible S100A8-S100A9 species was detected. Over time, the S100A9-S100A9 species became less abundant, while the amount of the S100A8-S100A9 species increased over the 23 -h time course. Moreover, in the presence of $\mathrm{Ca}(\mathrm{II})$, no band attributed to a disulfide-linked S100A8-S100A8 species was detected. We reason that the different disulfide reactivity likely results from $\mathrm{Ca}(\mathrm{II})$-induced structural changes that impact the accessibility of $\mathrm{C} 42$ of S100A8, which is located in the linker region between the $\mathrm{N}$ - and C-terminal EF-hands. In contrast, C3 of S100A9 is fully solvent exposed. Moreover, the conversion of S100A9-S100A9 species to the S100A8-S100A9 species at later time points indicates that disulfide bonds involving $\mathrm{C} 42$ of S100A8 are more stable. We also performed reactions with a $\mathrm{CP}$ variant that lacks $\mathrm{C} 3$ of S100A9 [S100A8/S100A9(C3S)] to mimic the truncated $\mathrm{CP}$ species observed in the human samples that results from translation initiation at M5 of S100A9. Non-reducing SDS-PAGE afforded no evidence for disulfide bond formation following treatment of the S100A8/S100A9(C3S) variant with $100 \mu \mathrm{M} \mathrm{H}_{2} \mathrm{O}_{2}$ (Figure S19). Because oxidation of $\mathrm{CP}$ in vivo is presumed to occur in the extracellular space, we further characterized $\mathrm{CP}$ after treatment with $100 \mu \mathrm{M} \mathrm{H}_{2} \mathrm{O}_{2}$ for $23 \mathrm{~h}$ in the presence of $\mathrm{Ca}(\mathrm{II})$, and we name this protein disulfide-linked $\mathrm{CP}$.

To further decipher the speciation of $\mathrm{CP}$ after exposure to $100 \mu \mathrm{M} \mathrm{H}_{2} \mathrm{O}_{2}$ for $23 \mathrm{~h}$ in the presence of excess $\mathrm{Ca}(\mathrm{II})$, we treated disulfide-linked CP with TCEP to reduce the disulfide bonds prior to mass spectrometry. The reaction product displayed the expected masses for unmodified S100A8 and S100A9, and no peaks that corresponded to species containing additional oxygen atoms were found (Figure S20). This analysis indicated that $100 \mu \mathrm{M}$ $\mathrm{H}_{2} \mathrm{O}_{2}$ is insufficient to oxidize the methionine residues of $\mathrm{CP}$ under our reaction conditions. Next, to assess the effects of $\mathrm{Ca}$ (II) ions and disulfide bond formation on protein oligomerization, we treated aliquots of the sample from the 23-h time point in three different ways and analyzed the samples by SEC and SDS-PAGE (Figure S21 and Supporting 
Discussion). We (i) removed $\mathrm{Ca}$ (II) ions from the protein using EDTA to examine the disulfide-containing species without bound $\mathrm{Ca}$ (II) ions, (ii) reduced the disulfide bonds using TCEP to examine the $\mathrm{Ca}$ (II)-bound reduced protein, and (iii) analyzed an untreated sample where the disulfide bonds remained intact and the protein was $\mathrm{Ca}$ (II)-bound. These experiments provided several new insights: (i) all species in the disulfide-linked $\mathrm{CP}$ mixture displayed $\mathrm{Ca}(\mathrm{II})$-induced oligomerization, (ii) the major species in the disulfide-linked $\mathrm{CP}$ mixture was the CP heterotetramer that contained at least one (S100A9)C3-(S100A8)C42 "intradimer" disulfide bond, and (iii) the minor product was a small disulfide-linked CP polymer. To the best of our knowledge, the existence of an intradimer disulfide bond has not been considered to date. Examination of CP-Ser crystal structures revealed that the Nterminus of S100A9 is in close proximity to (S100A8)C42 (Figure S22), indicating that formation of an (S100A9)C3-(S100A8)C42 intradimer disulfide bond is reasonable.

\section{Disulfide-Linked CP is Protease Sensitive.}

We assayed the susceptibility of disulfide-linked $\mathrm{CP}$ to degradation by trypsin in the presence of $\mathrm{Ca}$ (II). We quenched reaction aliquots in the absence and presence of TCEP at varying time points and analyzed the mixtures by HPLC (Figure 8B). At the $0 \mathrm{~h}$ time point, the chromatogram of the TCEP-treated sample exhibited two major peaks corresponding to S100A8 and S100A9, and the peak intensities decreased over time, indicating trypsincatalyzed degradation of each subunit (Figure 8B). The chromatogram of the sample that was not treated with a reductant was more complex and exhibited three major peaks along with a minor peak (Figure 8B). One of the major peaks ( $38.5 \mathrm{~min}$ ) was assigned to the S100A8 monomer, and the identities of the other two major peaks were determined by mass spectrometry (Figure 8B, Table S3). The 40.0 min peak was identified as the disulfide-linked S100A8-S100A9 dimer and the 41.1 min peak was identified as the disulfide-linked S100A9-S100A9 dimer. The minor peak (39.9 min) was assigned to the S100A9 monomer. Analysis of the samples obtained at later time points revealed several features about the trypsin susceptibility of these species: (i) $\mathrm{CP}$ containing an intradimer disulfide bond was almost completely degraded by trypsin after only $1 \mathrm{~h}$, (ii) the S100A9-S100A9 dimer was almost completely degraded after $23 \mathrm{~h}$, and (iii) the CP subunits that had not formed disulfide bonds were digested to a lesser extent than the disulfide-linked protein (Figure 8B). From these results, we concluded that disulfide bond formation between $\mathrm{CP}$ subunits sensitizes CP to proteolysis by trypsin, and that disulfides that involve C42 of S100A8 are particularly destabilizing.

\section{Disulfide-Linked CP and MetO-Disulfide-Linked CP are Degraded by Trypsin at Comparable Rates.}

With the knowledge that methionine oxidation sensitized CP to proteolysis by weakening noncovalent oligomerization, we sought to compare the stability of disulfide-linked $\mathrm{CP}$ and MetO-disulfide-linked CP. We therefore developed and optimized a two-step protocol to obtain MetO-disulfide-linked CP (Figures S20 and S23 and Supporting Discussion). We found that treating disulfide-linked $\mathrm{CP}$ for $7 \mathrm{~h}$ with $100 \mathrm{mM} \mathrm{H}_{2} \mathrm{O}_{2}$ afforded the sufficient Met oxidation to resemble $\mathrm{CP}$-Ser $\mathrm{O}_{4}$ and $\mathrm{CP}$-Ser $\mathrm{O}_{5}$ while minimally perturbing the disulfide bonds, and we named this reaction product MetO-disulfide-linked CP. We performed trypsin degradation assays, and at each time point, quenched samples in the 
absence and presence of TCEP. Without TCEP reduction, the HPLC trace of MetO-

disulfide-linked CP exhibited a broad peak, and we were unable to resolve individual species (Figure S24). In contrast, treatment of the protein with TCEP during the quench gave rise to a chromatogram reminiscent of CP-Ser $\mathrm{O}_{4}$ and CP-Ser $\mathrm{O}_{5}$ (Figure S24). We assigned the peaks at $36.5 \mathrm{~min}, 37.2 \mathrm{~min}$, and $37.7 \mathrm{~min}$ to $\mathrm{S} 100 \mathrm{~A} 9+4 \mathrm{O}$, S100A9+3O, and $\mathrm{S} 100 \mathrm{~A} 8+\mathrm{O}$ by LC-MS, respectively. The fraction containing S100A9+3O also contained a detectable amount of S100A8+2O.

We anticipated that MetO-disulfide-linked CP would be degraded more quickly than disulfide-linked CP given our observations with CP-Ser $\mathrm{O}_{4}$ and CP-Ser $\mathrm{O}_{5}$. Trypsin hydrolyzed MetO-disulfide-linked CP; however, comparison of the degradation of disulfidelinked CP and MetO-disulfide-linked CP revealed that they were degraded at comparable rates (Figure S22). We also noted that rapid degradation of disulfide-linked CP and MetOdisulfide-linked CP occurred during the first hour of digestion, and then markedly slowed.

\section{Discussion}

This work demonstrates that post-translational oxidation of $\mathrm{CP}$ has structural and functional consequences. In particular, methionine oxidation and disulfide-bond formation alter the stability of CP to proteases. This work also highlights the complex speciation of $\mathrm{CP}$ in the biological milieu. Prior studies have considered speciation of CP primarily from the standpoint of the metalation. ${ }^{8,10,24,25,49}$ When one considers the potential diversity of CP arising from combinations of metalation and post-translational modifications, it becomes clear that the CP present at an infection site is likely highly heterogeneous. Our results support hypotheses for biological fates of $\mathrm{CP}$ that are directed by oxidation and metal speciation.

In agreement with prior studies that reported methionine-oxidized CP subunits in samples from mice and humans, ${ }^{29-32}$ we detected oxidized CP subunits in samples of human nasal mucus and human pus. Moreover, by using ${ }^{15} \mathrm{~N}$-labeled CP-Ser as an internal standard to report on adventitious methionine oxidation, we obtained compelling support for the formation and relevance of methionine-oxidized $\mathrm{CP}$ in vivo. $\mathrm{CP}$ is an abundant neutrophil protein that is released into the extracellular space, and methionine oxidation of CP likely results from the neutrophil oxidative burst. This process occurs after neutrophil activation, and leads to production of ROS including $\mathrm{O}_{2}{ }^{--}, \mathrm{H}_{2} \mathrm{O}_{2}$, and $\mathrm{HOCl} .{ }^{33}$ Indeed, neutrophil activation increases methionine oxidation of neutrophil proteins and surrounding tissues, 35,50 and a 1-proteinase inhibitor is inactivated by methionine oxidation caused by neutrophil-derived ROS in vivo. ${ }^{34}$ Under certain circumstances, microbes may also cause oxidation of $\mathrm{CP}$ as an immune-evasion strategy. For instance, Helicobacter pylori can induce ROS generation in epithelial cells and macrophages, ${ }^{51,52}$ which could modify $\mathrm{CP}$ and result in its premature degradation.

In this study, we employed $\mathrm{H}_{2} \mathrm{O}_{2}$ to oxidize $\mathrm{CP}$ and CP-Ser because it is more selective for Met and Cys oxidation than other oxidants. ${ }^{43}$ We recognize that the time and $\mathrm{H}_{2} \mathrm{O}_{2}$ concentrations required to oxidize $\mathrm{CP}$ in our experiments raise questions of kinetic competence in vivo. Indeed, an estimate of $\mathrm{H}_{2} \mathrm{O}_{2}$ in a neutrophil phagosome is between 1 to 
$4 \mu \mathrm{M},{ }^{53}$ far below the concentrations we employed to obtained oxidized CP(-Ser) species. It is important to note that the primary oxidant during the neutrophil oxidative burst is $\mathrm{HOCl}$ produced by MPO. Although $\mathrm{H}_{2} \mathrm{O}_{2}$ is thermodynamically a strong oxidant, it is kinetically slow with a rate constant of $6 \times 10^{-3} \mathrm{M}-1 \mathrm{~s}^{-1}$ for oxidizing Met to MetO. ${ }^{36}$ In contrast, the rate constant for $\mathrm{HOCl}$ reacting with Met to form MetO is $3.8 \times 10^{7} \mathrm{M}^{-1} \mathrm{~s}^{-1}$. ${ }^{36}$ Due to the extremely fast reactivity of $\mathrm{HOCl}$ with Met, we reason that this oxidant may be responsible for producing the majority of the oxidized methionine residues observed in CP. With the results reported here as a foundation for future work, investigations of the consequences of $\mathrm{HOCl}$ and chloramines for the structure and function of CP-Ser and $\mathrm{CP}$ are warranted.

By using $\mathrm{H}_{2} \mathrm{O}_{2}$, we found that oxidation of M81 of S100A9 perturbed the dimer-tetramer equilibrium in the presence of $\mathrm{Ca}(\mathrm{II})$. Crystal structures of the $\mathrm{CP}$ heterotetramer show that the side chain of M81 of S100A9 points directly into the dimer-dimer interface (Figure S2). Thus, we expect that conversion of Met to MetO decreases the driving force for tetramerization due to the hydrophilic nature of MetO, which is considerably more hydrophilic than Met. Indeed, MetO was calculated to be approximately as hydrophilic as lysine. ${ }^{54}$ Protease susceptibility assays performed in the presence of excess $\mathrm{Ca}$ (II) ions revealed that both $\mathrm{CP}-\mathrm{Ser} \mathrm{O}_{4}$ and $\mathrm{CP}-\mathrm{Ser} \mathrm{O}_{5}$ were more rapidly degraded by trypsin, chymotrypsin, and proteinase $\mathrm{K}$, which we attribute to incomplete tetramerization caused by oxidation of M81 of S100A9. Protease resistance was rescued by addition of one equivalent of $\mathrm{Mn}$ (II) to CP-Ser $\mathrm{O}_{4}$ and $\mathrm{CP}$-Ser $\mathrm{O}_{5}$, which coordinated to the $\mathrm{His}_{6}$ site and caused the proteins to tetramerize. Thus, the increased protease resistance conferred by $\mathrm{Mn}$ (II) or $\mathrm{Fe}$ (II) binding results from the metal ion converting $\mathrm{CP}-\mathrm{Ser} \mathrm{O}_{4}$ and $\mathrm{CP}-\mathrm{Ser} \mathrm{O}_{5}$ to the tetrameric state. ${ }^{12}$ The protease susceptibility assays also revealed that, in the presence of excess $\mathrm{Ca}(\mathrm{II})$ ions, $\mathrm{CP}$-Ser $\mathrm{O}_{4}$ and $\mathrm{CP}-\mathrm{Ser} \mathrm{O}_{5}$ were poor substrates for HNE. It is possible that the low activity of $\mathrm{HNE}$ against CP-Ser $\mathrm{O}_{4}$ and CP-Ser $\mathrm{O}_{5}$, as well as CP-Ser, reflects a selected trait of CP. HNE and CP are both released by neutrophils, and we can imagine that that resisting degradation by $\mathrm{HNE}$ allows $\mathrm{CP}$ to perform its function without being immediately degraded.

Native CP presents a more complex scenario because each full-length subunit contains a single cysteine residue that is susceptible to oxidation. By investigating the consequences of oxidative post-translational modifications to the native protein, we demonstrated that disulfide-bond formation between $\mathrm{CP}$ molecules also increased the rate of protease degradation. This effect was especially pronounced for the species containing the S100A8S100A9 disulfide linkage, but the S100A9-S100A9 disulfide-linked protein was also degraded faster than CP-Ser. We propose that disulfide bonds involving S100A8 are destabilizing because $\mathrm{C} 42$ of S100A8 is located in the "hinge" region between the N-and Cterminal EF-hands. Considering the oxidative nature of the extracellular space and the ROS generated during the neutrophil response, it is reasonable to imagine that $\mathrm{CP}$ can form disulfide bonds with other $\mathrm{CP}$ molecules as well as other cysteine-containing biomolecules. Along these lines, human S100A7 was found to form high-molecular weight disulfide-linked oligomers in wounds. ${ }^{55}$ Amino acid sequence alignment of S100A8 polypeptides from 36 available genomes shows that $\mathrm{C} 42$ of S100A8 is highly conserved (Figure S25). This residue is surface exposed in human CP, which is unusual for Cys residues, ${ }^{56}$ and is likely surface exposed in orthologues from other mammals. Thus, it is possible that disulfide bond formation with S100A8 enhances the protease susceptibility of CP in many organisms. 
Although disulfide bonding increased protease susceptibility more than Met oxidation, we expect that Met oxidation can influence the lifetime of $\mathrm{CP}$ at biological sites. Ex vivo analyses of human kidney stones ${ }^{32}$ and our work indicate that there is a significant population of S100A9 that lacks the first 5 amino acids and thus the Cys residue at position 3. This truncated S100A9 species cannot form disulfides that afford enhanced protease susceptibility, and we reason that methionine oxidation may accelerate clearance of $\mathrm{CP}$ containing this truncated S100A9 subunit.

Taken together, the investigations of CP and CP-Ser presented in this work afford an extension to the working model of CP (Figure 9). Previously, CP was thought to reside in the extracellular space as the $\mathrm{Ca}(\mathrm{II})$-bound tetramer, with some fraction also coordinated to one or more transition metals. We propose a more dynamic picture where methionine oxidation and disulfide bonds modulate the quaternary structure and thus lifetime of $\mathrm{CP}$ in this milieu by enhancing the susceptibility of $\mathrm{Ca}(\mathrm{II})$-bound $\mathrm{CP}$ to proteolytic degradation. $\mathrm{CP}$ is multifunctional, and after its release, the host must attempt to balance its nutrient withholding role against its contributions to proinflammatory signaling. We hypothesize that Met oxidation helps the host achieve this balance. Because the concentration of $\mathrm{CP}$ at an infection site is expected to exceed the concentration of bioavailable transition metal ions, we expect that the majority of $\mathrm{CP}$ exists in the $\mathrm{Ca}$ (II)-bound state and is thus susceptible to proteolytic degradation after post-translational oxidation. We reason that recovery of protease stability after binding a metal at the $\mathrm{His}_{6}$ site is advantageous for the host because it prevents premature release of transition metal ions. This scenario would allow the host to preferentially degrade excess or "unnecessary" $\mathrm{CP}$ while preserving $\mathrm{CP}$ that is actively withholding transition metal ions. Removing CP is likely important for preventing it from participating in inflammatory shock and the development of autoreactive $\mathrm{CD} 8^{+} \mathrm{T}$ cells. ${ }^{18,19}$

Beyond the context of $\mathrm{CP}$ in the host/microbe interaction and inflammation, this work agrees with previous work on the MetO post-translational modification. Various structural consequences of methionine oxidation have been described. For instance, the presence of MetO can disrupt interactions between protein domains, ${ }^{57,58}$ hinder formation of noncovalent heterocomplexes, ${ }^{34,59}$ and destabilize protein folds. ${ }^{60}$ In addition, the connection between MetO and accelerated proteolysis has precedence. Met oxidation of calmodulin targeted it to the proteasome in an ubiquitin-independent fashion; ${ }^{61}$ in contrast, our work demonstrated that Met oxidation of $\mathrm{CP}$ accelerated non-targeted proteolysis. Lastly, the Met/MetO redox couple in the context of ROS have been considered to serve an antioxidant role. ${ }^{38,39}$ The hypothesis is that surface Met residues are oxidized to MetO, which can be reduced to methionine by Msr proteins, thereby protecting critical residues from ROS. Although we agree that Met can play an important sacrificial antioxidant function, our data and those of others also support a regulatory role for Met oxidation. ${ }^{57,62}$ Considering the observation that ROS enable neutrophil proteases to be active in the extracellular space by oxidizing Met to MetO,34 the necessity for ROS to form neutrophil extracellular traps, ${ }^{63}$ and our finding that MetO modification sensitizes CP to proteolysis argues in favor of ROS and MetO also serving as signals during the immune response.

In closing, the results presented in this work support a model where methionine oxidation and disulfide bond formation promote proteolytic degradation of $\mathrm{CP}$, providing new 
molecular-level insights into the fate of $\mathrm{CP}$ after release into the extracellular space. We propose that the host uses oxidative modification of $\mathrm{CP}$ to accelerate its proteolysis. We envision that, by sensitizing $\mathrm{CP}$ to proteolysis, the host can dispose of $\mathrm{CP}$ in a timely manner to prevent negative outcomes from CP-mediated proinflammatory signaling. Moreover, because transition-metal binding rescues tetramerization and protease resistance, it appears that the host strategically avoids degrading transition-metal-bound CP to prevent release of nutrients to microbes.

\section{Supplementary Material}

Refer to Web version on PubMed Central for supplementary material.

\section{Acknowledgements}

We thank the NIH (R01GM118695), the MIT Research Support Committee (Wade Award), and the MIT Department of Chemistry for financial support. The MIT Biophysical Instrumentation Facility for the Study of Complex Macromolecular Systems is supported by NSF grant 0070319. We thank Prof. B. L. Pentelute for generously providing access to mass spectrometry instrumentation, Dr. A. Vinogradov for his assistance with mass spectrometry, and Ms. A. Nocera for technical assistance with the human nasal mucus samples.

\section{References}

(1). Steinbakk M; Naess-Andresen C-F; Lingaas E; Dale I; Brandtzaeg P; Fagerhol MK Lancet 1990, 336, 763-765. [PubMed: 1976144]

(2). Hood MI; Skaar EP Nat. Rev. Microbiol 2012, 10, 525-537. [PubMed: 22796883]

(3). Corbin BD; Seeley EH; Raab A; Feldmann J; Miller MR; Torres VJ; Anderson KL; Dattilo BM; Dunman PM; Gerads R; Caprioli RM; Nacken W; Chazin WJ; Skaar EP Science 2008, 319, 962965. [PubMed: 18276893]

(4). Johne B; Fagerhol MK; Lyberg T; Prydz H; Brandtzaeg P; Naess-Andresen CF; Dale I J. Clin. Pathol.: Mol. Pathol 1997, 50, 113-123.

(5). Edgeworth J; Gorman M; Bennett R; Freemont P; Hogg N J. Biol. Chem 1991, 266, 7706-7713. [PubMed: 2019594]

(6). Fagerhol MK; Dale I; Andersson T Scand. J. Haemotol 1980, 24, 393-398.

(7). Damo SM; Kehl-Fie TE; Sugitani N; Holt ME; Rathi S; Murphy WJ; Zhang Y; Betz C; Hench L; Fritz G; Skaar EP; Chazin WJ Proc. Natl. Acad. Sci. U.S.A 2013, 110, 3841-3846. [PubMed: 23431180]

(8). Brophy MB; Hayden JA; Nolan EM J. Am. Chem. Soc 2012, 134, 18089-18100. [PubMed: 23082970]

(9). Brophy MB; Nakashige TG; Gaillard A; Nolan EM J. Am. Chem. Soc 2013, 135, 17804-17817. [PubMed: 24245608]

(10). Nakashige TG; Zhang B; Krebs C; Nolan EM Nat. Chem. Biol 2015, 11, 765-771. [PubMed: 26302479]

(11). Nakashige TG; Stephan JR; Cunden LS; Brophy MB; Wommack AJ; Keegan BC; Shearer JM; Nolan EM J. Am. Chem. Soc 2016, 138, 12243-12251. [PubMed: 27541598]

(12). Stephan JR; Nolan EM Chem. Sci 2016, 7, 1962-1975. [PubMed: 26925211]

(13). Garcia YM; Barwinska-Sendra A; Tarrant E; Skaar EP; Waldron KJ; Kehl-Fie TE PLOS Pathog 2017, 13, e1006125. [PubMed: 28103306]

(14). Liu JZ; Jellbauer S; Poe AJ; Ton V; Pesciaroli M; Kehl-Fie TE; Restrepo Nicole A.; Hosking MP; Edwards RA; Battistoni A; Pasquali P; Lane TE; Chazin WJ; Vogl T; Roth J; Skaar EP; Raffatellu M Cell Host \& Microbe 2012, 11, 227-239. [PubMed: 22423963] 
(15). Nairn BL; Lonergan ZR; Wang J; Braymer JJ; Zhang Y; Calcutt MW; Lisher JP; Gilston BA; Chazin WJ; de Crécy-Lagard V; Giedroc DP; Skaar EP Cell Host \& Microbe 2016, 19, 826-836. [PubMed: 27281572]

(16). Stork M; Grijpstra J; Bos MP; Mañas Torres C; Devos N; Poolman JT; Chazin WJ; Tommassen J PLOS Pathog 2013, 9, e1003733. [PubMed: 24204275]

(17). Jean S; Juneau RA; Criss AK; Cornelissen CN Infect. Immun 2016, 84, 2982-2994. [PubMed: 27481245]

(18). Vog1 T; Tenbrock K; Ludwig S; Leukert N; Ehrhardt C; van Zoelen MAD; Nacken W; Foell D; van der Poll T; Sorg C; Roth J Nat. Med 2007, 13, 1042-1049. [PubMed: 17767165]

(19). Loser K; Vogl T; Voskort M; Lueken A; Kupas V; Nacken W; Klenner L; Kuhn A; Foell D; Sorokin L; Luger TA; Roth J; Beissert S Nat. Med 2010, 16, 713-717. [PubMed: 20473308]

(20). Austermann J; Friesenhagen J; Fassl SK; Ortkras T; Burgmann J; Barczyk-Kahlert K; Faist E; Zedler S; Pirr S; Rohde C; Müller-Tidow C; von Köckritz-Blickwede M; von Kaisenberg CS; Flohé SB; Ulas T; Schultze JL; Roth J; Vogl T; Viemann D Cell Reports 2014, 9, 2112-2123. [PubMed: 25497086]

(21). Gagnon DM; Brophy MB; Bowman SEJ; Stich TA; Drennan CL; Britt RD; Nolan EM J. Am. Chem. Soc 2015, 137, 3004-3016. [PubMed: 25597447]

(22). Hunter MJ; Chazin WJ J. Biol. Chem 1998, 273, 12427-12435. [PubMed: 9575199]

(23). Korndörfer IP; Brueckner F; Skerra AJ Mol. Biol 2007, 370, 887-898.

(24). Hayden JA; Brophy MB; Cunden LS; Nolan EM J. Am. Chem. Soc 2013, 135, 775-787. [PubMed: 23276281]

(25). Nakashige TG; Zygiel EM; Drennan CL; Nolan EM J. Am. Chem. Soc 2017, 139, 8828-8836. [PubMed: 28573847]

(26). Vogl T; Roth J; Sorg C; Hillenkamp F; Strupat K J. Am. Soc. Mass Spectrom 1999, 10, 1124 1130. [PubMed: 10536818]

(27). Vogl T; Leukert N; Barczyk K; Strupat K; Roth J Biochim. Biophys. Acta 2006, 1763, 12981306. [PubMed: 17050004]

(28). Brini M; Ottolini D; Calì T; Carafoli E Met. Ions Life Sci 2013, 13, 81-137. [PubMed: 24470090]

(29). Spraggins JM; Rizzo DG; Moore JL; Rose KL; Hammer ND; Skaar EP; Caprioli RM J. Am. Soc. Mass Spectrom 2015, 26, 974-985. [PubMed: 25904064]

(30). Magon NJ; Turner R; Gearry RB; Hampton MB; Sly PD; Kettle AJ Free Radic. Biol. Med 2015, 86, 133-144. [PubMed: 26006104]

(31). Gomes LH; Raftery MJ; Yan WX; Goyette JD; THomas PS; Geczy CL Free Radic. Biol. Med 2013, 58, 170-186. [PubMed: 23277148]

(32). Martelli C; Marzano V; Iavarone F; Huang L; Vincenzoni F; Desiderio C; Messana I; Beltrami P; Zattoni F; Ferraro PM; Buchholz N; Locci G; Faa G; Castagnola M; Gambaro G J. Urol 2016, 196, 911-918. [PubMed: 27113968]

(33). Nathan C Nat. Rev. Immunol 2006, 6, 173-182. [PubMed: 16498448]

(34). Weiss SJ N. Engl. J. Med 1989, 320, 365. [PubMed: 2536474]

(35). Maier K; Leuschel L; Costabel U Am. Rev. Respir. Dis 1991, 143, 271-274. [PubMed: 1990939]

(36). Davies MJ Biochim. Biophys. Acta 2005, 1703, 93-109. [PubMed: 15680218]

(37). Levine RL; Mosoni L; Berlett BS; Stadtman ER Proc. Natl. Acad. Sci. U.S.A 1996, 93, 1503615040. [PubMed: 8986759]

(38). Moskovitz J; Berlett BS; Poston JM; Stadtman ER Proc. Natl. Acad. Sci. U.S.A 1997, 94, 95859589. [PubMed: 9275166]

(39). Levine RL; Berlett BS; Moskovitz J; Mosoni L; Stadtman ER Mech. Ageing Dev 1999, 107, 323-332. [PubMed: 10360685]

(40). Achilli C; Ciana A; Rossi A; Balduini C; Minetti G J. Leukoc. Biol 2007, 83, 181-189. [PubMed: 17938273]

(41). Stadtman ER; Van Remmen H; Richardson A; Wehr NB; Levine RL Biochim. Biophys. Acta 2005, 1703, 135-140. [PubMed: 15680221] 
(42). Lim SY; Raftery MJ; Goyette J; Hsu K; Geczy CL J. Leukoc. Biol 2009, 86, 577-587. [PubMed: 19237640]

(43). Winterbourn CC Methods Enzynol 2013, 528, 3-25.

(44). Brown PH; Balbo A; Schuck P In Current Protocols in Immunology; John Wiley \& Sons, Inc: 2001, 1815.1-18.15.39.

(45). Lebowitz J; Lewis MS; Schuck P Protein Sci 2002, 11, 2067-2079. [PubMed: 12192063]

(46). Stafford WF Anal. Biochem 1992, 203, 295-301. [PubMed: 1416025]

(47). Philo JS Anal. Biochem 2006, 354, 238-246. [PubMed: 16730633]

(48). Walkup GK; Burdette SC; Lippard SJ; Tsien RY J. Am. Chem. Soc 2000, 122, 5644-5645.

(49). Hadley RC; Gagnon DM; Brophy MB; Gu Y; Nakashige TG; Britt RD; Nolan EM J. Am. Chem. Soc 2018, 140, 110-113. [PubMed: 29211955]

(50). Fliss H; Weissbach H; Brot N Proc. Natl. Acad. Sci. U.S.A 1983, 80, 7160-7164. [PubMed: 6580633]

(51). Obst B; Wagner S; Sewing KF; Beil W Carcinogenesis 2000, 21, 1111-1115. [PubMed: 10836997]

(52). Chaturvedi R; Cheng Y; Asim M; Bussière FI; Xu H; Gobert AP; Hacker A; Casero RA; Wilson KT J. Biol. Chem 2004, 279, 40161-40173. [PubMed: 15247269]

(53). Imlay JA EcoSal Plus 2009, 3, ecosalplus 5.4.4.

(54). Black SD; Mould DR Anal. Biochem 1991, 193, 72-82. [PubMed: 2042744]

(55). Lee KC; Eckert RL J. Investig. Dermatol 2007, 127, 945-957. [PubMed: 17159909]

(56). Janin J; Miller S; Chothia C J. Mol. Biol 1988, 204, 155-164. [PubMed: 3216390]

(57). Ciorba MA; Heinemann SH; Weissbach H; Brot N; Hoshi T Proc. Natl. Acad. Sci. U.S.A 1997, 94, 9932-9937. [PubMed: 9275229]

(58). Snijder J; Rose RJ; Raijmakers R; Heck AJR J. Struct. Biol 2011, 174, 187-195. [PubMed: 21156208]

(59). Bertolotti-Ciarlet A; Wang W; Lownes R; Pristatsky P; Fang Y; McKelvey T; Li Y; Li Y; Drummond J; Prueksaritanont T; Vlasak J Mol. Immunol 2009, 46, 1878-1882. [PubMed: 19269032]

(60). Gao J; Yin DH; Yao Y; Sun H; Qin Z; Schöneich C; Williams TD; Squier TC Biophys. J 1998, 74, 1115-1134. [PubMed: 9512014]

(61). Balog EM; Lockamy EL; Thomas DD; Ferrington DA Biochemistry 2009, 48, 3005-3016. [PubMed: 19231837]

(62). Erickson JR; Joiner M.-1. A.; Guan X; Kutschke W; Yang J; Oddis CV; Bartlett RK; Lowe JS; O’Donnell SE; Aykin-Burns N; Zimmerman MC; Zimmerman K; Ham A-JL; Weiss RM; Spitz DR; Shea MA; Colbran RJ; Mohler PJ; Anderson ME Cell 2008, 133, 462-474. [PubMed: 18455987]

(63). Brinkmann V; Zychlinsky A Nat. Rev. Microbiol 2007, 5, 577-582. [PubMed: 17632569]

J Am Chem Soc. Author manuscript; available in PMC 2019 December 19. 


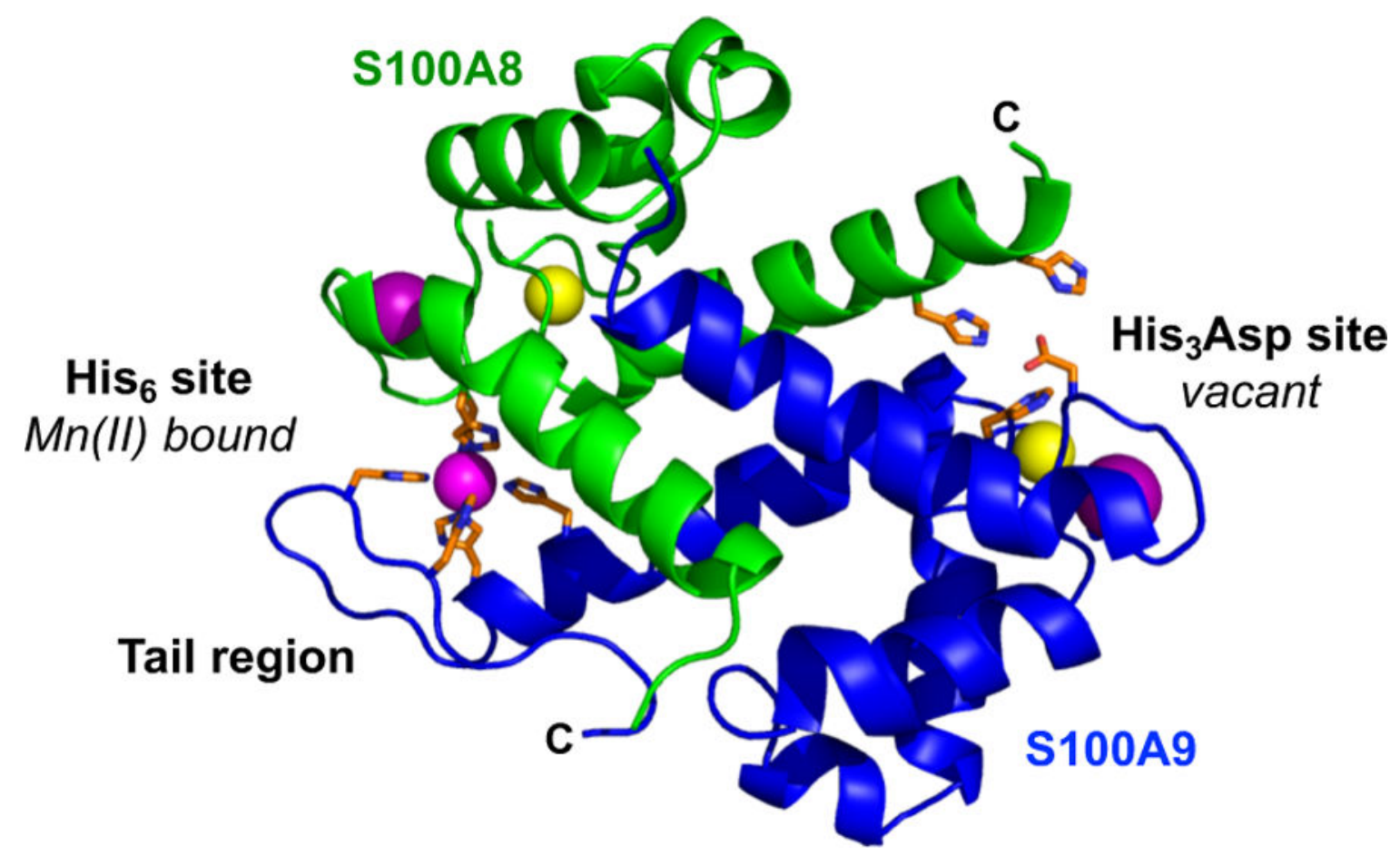

Figure 1.

A heterodimer unit from the crystal structure (PDB: 1XK4) of $\mathrm{Mn}$ (II)-, $\mathrm{Ca}(\mathrm{II})-$, and $\mathrm{Na}(\mathrm{I})$ bound CP-Ser. ${ }^{21}$ The green and blue chains are S100A8 and S100A9, respectively. Mn(II), $\mathrm{Ca}(\mathrm{II})$, and $\mathrm{Na}(\mathrm{I})$ ions are shown in magenta, yellow, and purple, respectively. The transition-metal binding residues are shown with orange sticks. 


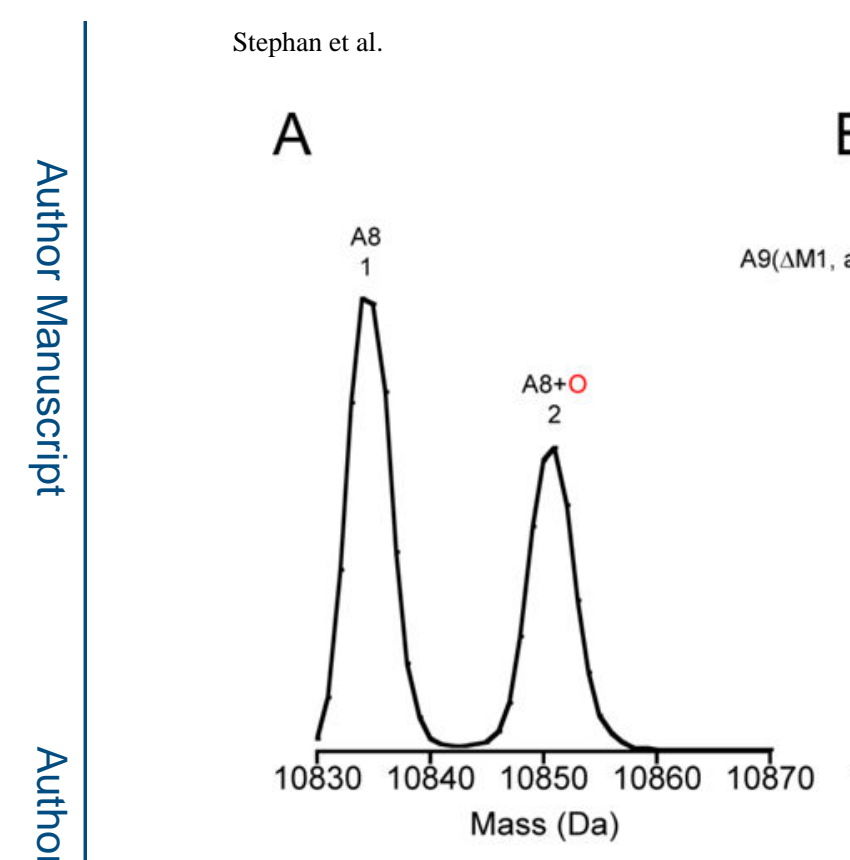

B

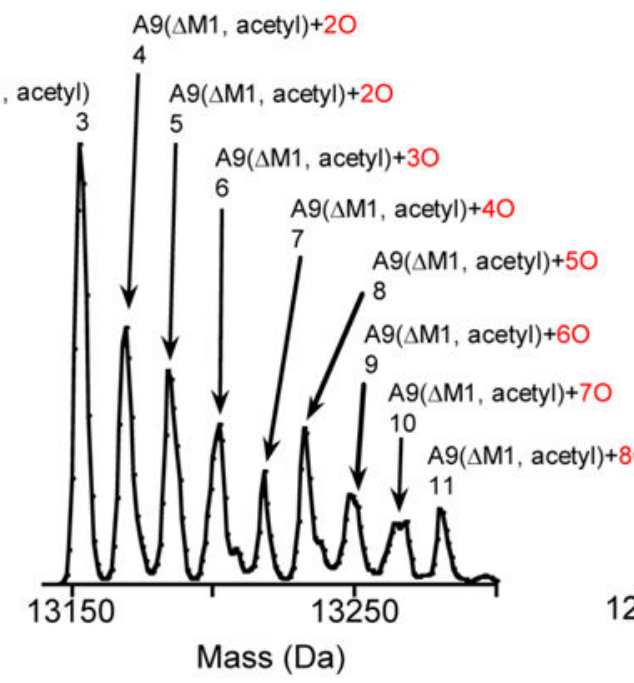

C

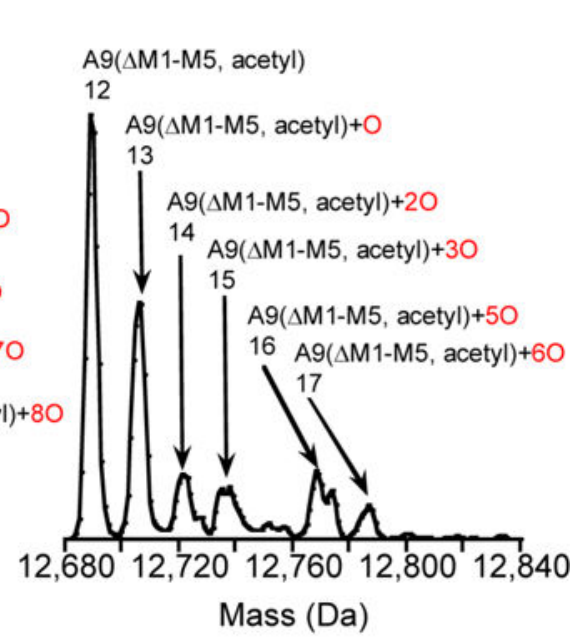

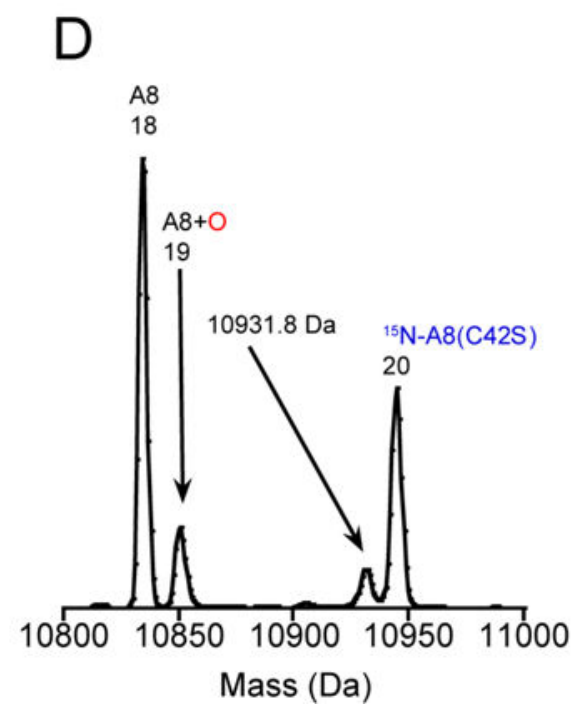

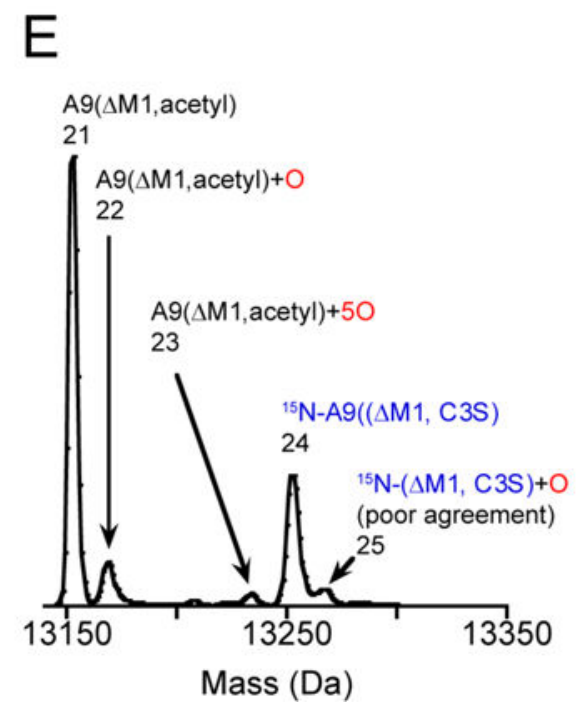

Figure 2.

Deconvoluted mass spectra of human nasal mucus. The S100A8 panels are normalized to the unmodified S100A8 peak and S100A9 panels are normalized to the most abundant S100A9 peak. The observed and theoretical masses for each numbered peak are listed in Table S1. Data from (A) mucus sample 2 expanded around S100A8, (B) mucus sample 2 expanded around S100A9, (C) mucus sample 2 expanded around S100A9( $\Delta \mathrm{M} 1-5)$, (D) mucus sample 22 expanded around S100A8 that shows ${ }^{15} \mathrm{~N}-\mathrm{A} 8(\mathrm{C} 42 \mathrm{~S})$, (E) mucus sample 22 expanded around S100A9 that shows ${ }^{15} \mathrm{~N}-\mathrm{A} 9(\Delta \mathrm{M} 1, \mathrm{C} 3 \mathrm{~S})$. 

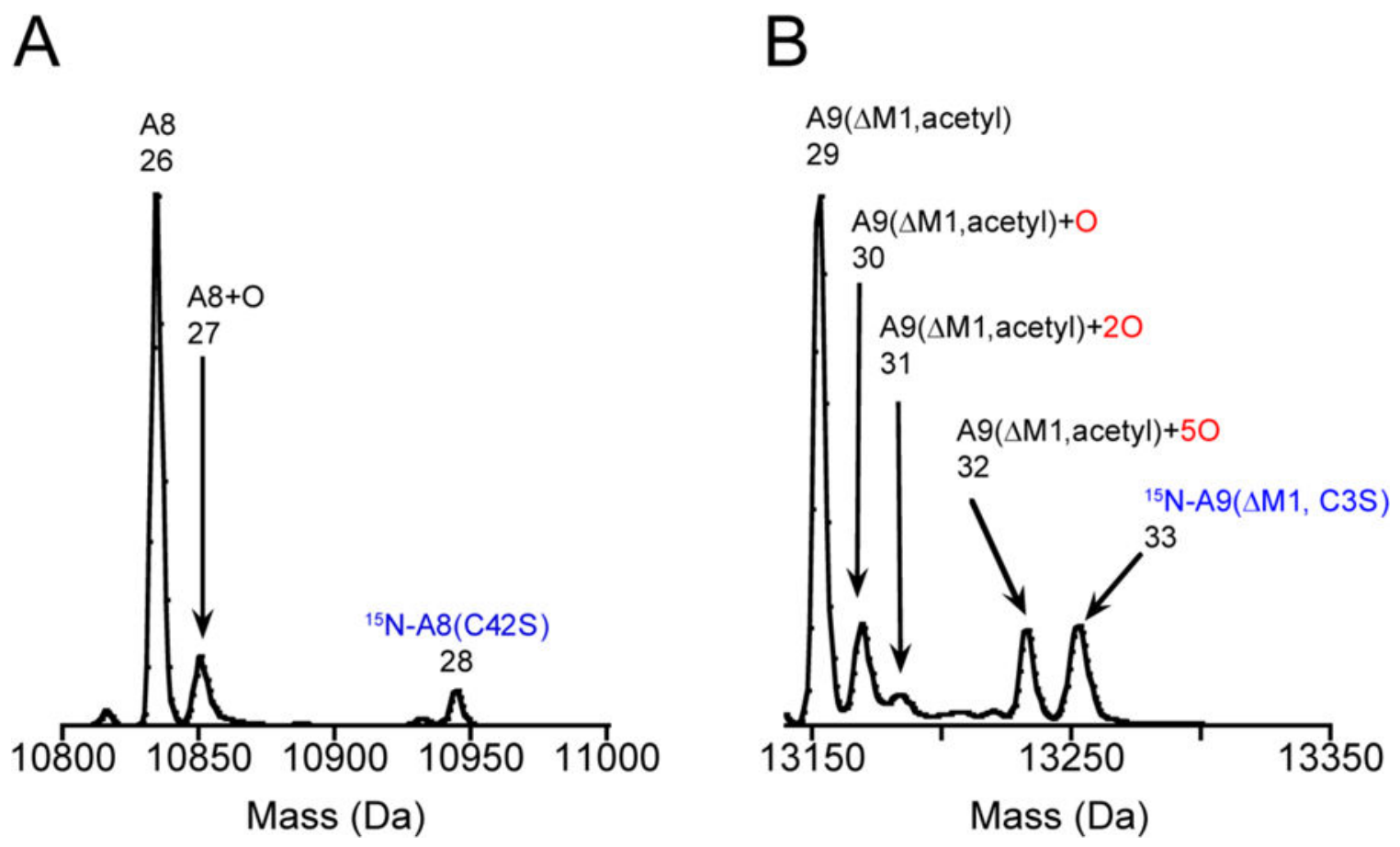

Figure 3.

Deconvoluted mass spectra of human pus with ${ }^{15} \mathrm{~N}-\mathrm{CP}-\mathrm{Ser}$ added immediately after collection. The observed and theoretical masses for each numbered peak are contained in Table S1. Data from pus sample 2 (A) expanded around S100A8 and (B) expanded around S100A9. 


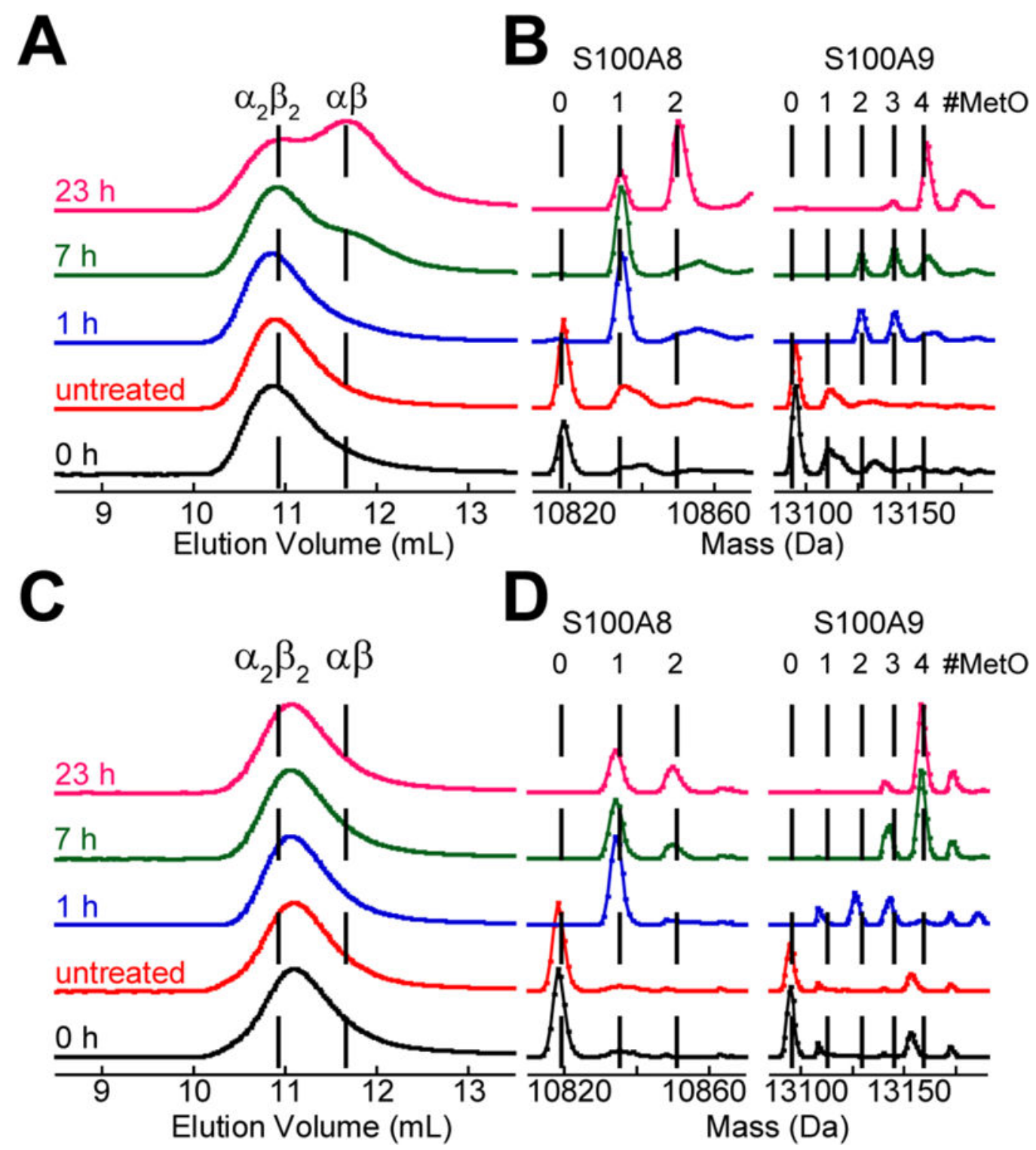

Figure 4.

SEC chromatograms and corresponding deconvoluted mass spectra of $30 \mu \mathrm{M}$ CP-Ser treated with $100 \mathrm{mM} \mathrm{H}_{2} \mathrm{O}_{2}$ in the presence of $1.5 \mathrm{mM} \mathrm{Ca}$ (II) or both $1.5 \mathrm{mM} \mathrm{Ca}$ (II) and $30 \mu \mathrm{M}$ Mn(II) (75 mM HEPES, $100 \mathrm{mM} \mathrm{NaCl}, \mathrm{pH} 7.5$ ). In the mass spectra, the dashed lines represent the expected masses of the $\mathrm{CP}$ subunits with additional oxygen atoms. The chromatograms and mass spectra were normalized to a maximum value of 1 . The listed times correspond to the duration of treatment with $\mathrm{H}_{2} \mathrm{O}_{2}$ prior to sample analysis. The untreated sample was incubated at $37^{\circ} \mathrm{C}$ for $23 \mathrm{~h}$. (A) SEC chromatograms for the $\mathrm{Ca}$ (II) only samples. (B) Regions of the deconvoluted mass spectra showing the S100A8 and S100A9 subunits for the $\mathrm{Ca}$ (II) only samples. (C) +Ca(II)+Mn(II) SEC. (C) SEC chromatograms for the $\mathrm{Ca}$ (II) and $\mathrm{Mn}$ (II) samples. (D) Regions of the deconvoluted mass spectra showing the S100A8 and S100A9 subunits for the $\mathrm{Ca}$ (II) and $\mathrm{Mn}$ (II) samples. In the 
SEC chromatograms, the $\mathrm{Mn}$ (II)- and $\mathrm{Ca}(\mathrm{II})$-bound CP-Ser tetramer elutes slightly later than the $\mathrm{Ca}(\mathrm{II})$-bound $\mathrm{CP}-\mathrm{Ser}$ tetramer. 
$\alpha_{2} \beta_{2} \quad \alpha \beta$

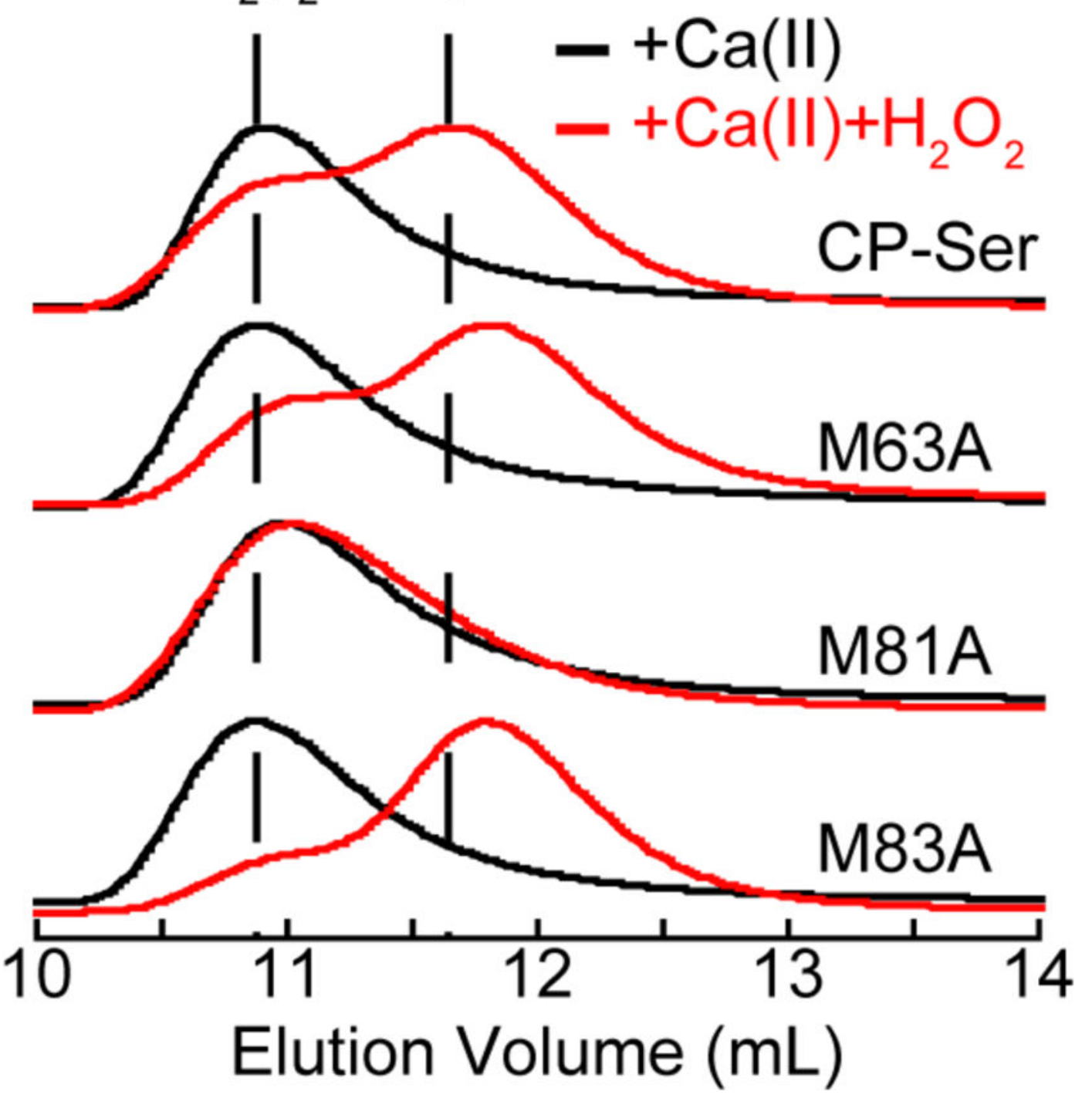

Figure 5.

SEC chromatograms of $30 \mu \mathrm{M} \mathrm{CP-Ser}$ and the Met-to-Ala variants in the presence of 1.5 $\mathrm{mM} \mathrm{Ca}$ (II) before (black traces) and after (red traces) treatment with $500 \mathrm{mM} \mathrm{H}_{2} \mathrm{O}_{2}$ for $7 \mathrm{~h}$ (75 mM HEPES, $100 \mathrm{mM} \mathrm{NaCl}, \mathrm{pH}$ 7.5). Each chromatogram was normalized to a maximum absorbance of 1 . 

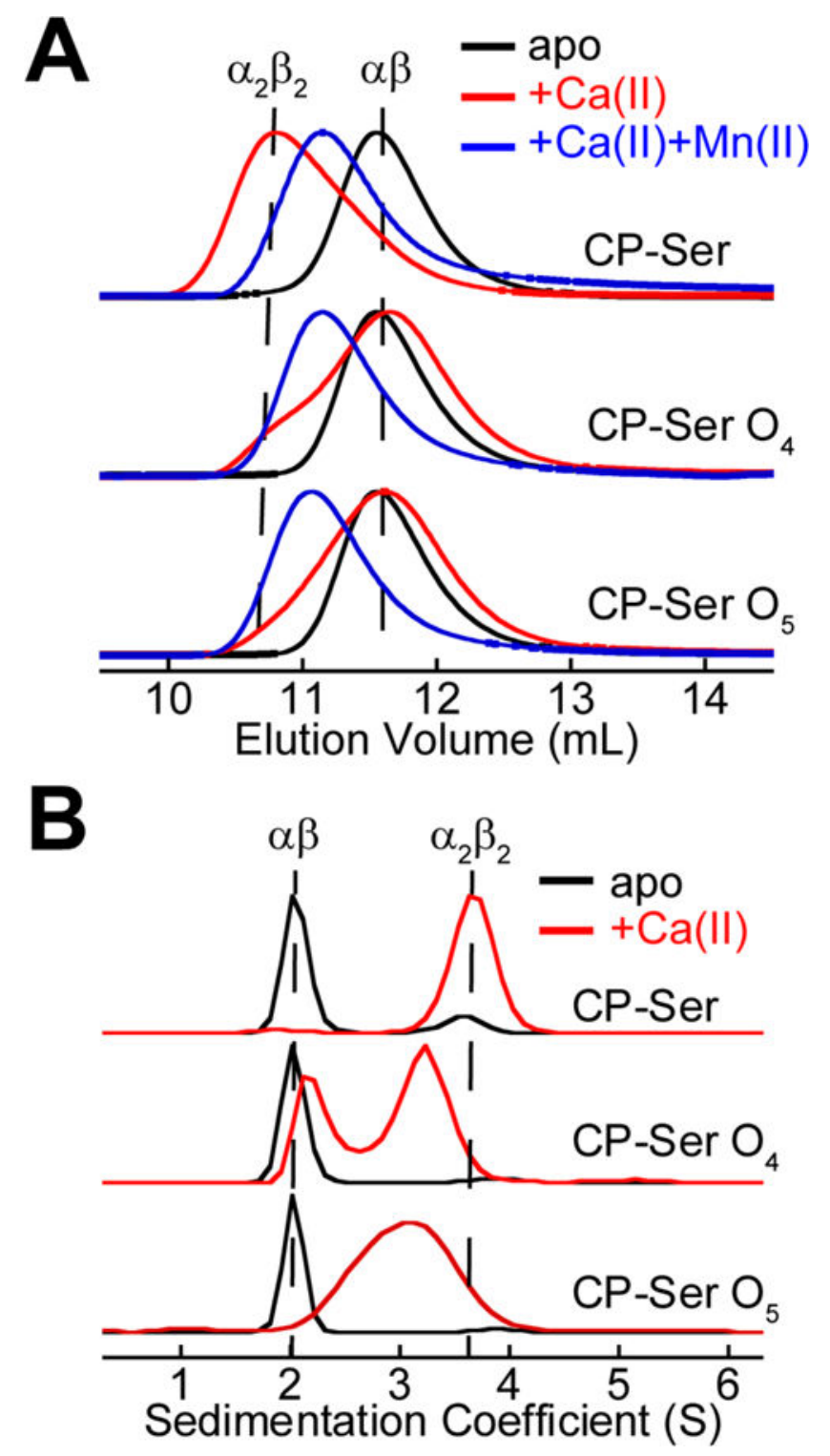

Figure 6.

Biophysical characterization of oxidized CP-Ser. (A) SEC chromatograms of $30 \mu \mathrm{M} \mathrm{CP-Ser,}$ $\mathrm{CP}-\mathrm{Ser} \mathrm{O}_{4}$, and $\mathrm{CP}-\mathrm{Ser}_{5}$ in the absence and presence of $1.5 \mathrm{mM} \mathrm{Ca}(\mathrm{II})$ only or $1.5 \mathrm{mM}$ $\mathrm{Ca}(\mathrm{II})$ and $30 \mu \mathrm{M} \mathrm{Mn}(\mathrm{II})$ (75 mM HEPES, $\left.100 \mathrm{mM} \mathrm{NaCl}, \mathrm{pH} 7.5,20^{\circ} \mathrm{C}\right)$. Each chromatogram was normalized to a maximum absorbance of 1 . The dashed lines represent the elution volumes of the tetramer and dimer. (B) Sedimentation velocity distributions of 30 $\mu \mathrm{M}$ CP-Ser, CP-Ser $\mathrm{O}_{4}$, and CP-Ser $\mathrm{O}_{5}$ in the absence and presence of $600 \mu \mathrm{M} \mathrm{Ca}(\mathrm{II})$ analyzed by SEDFIT using the $c(s)$ model (75 mM HEPES, $100 \mathrm{mM} \mathrm{NaCl}, \mathrm{pH} \mathrm{7.5,} 20{ }^{\circ} \mathrm{C}$ ). The peaks were normalized to a maximum value of 1 . The dashed lines represent the $S$ value of the dimer and tetramer. In the experiments with apo protein (black traces), $30 \mu \mathrm{M}$ EDTA was added to the samples. 


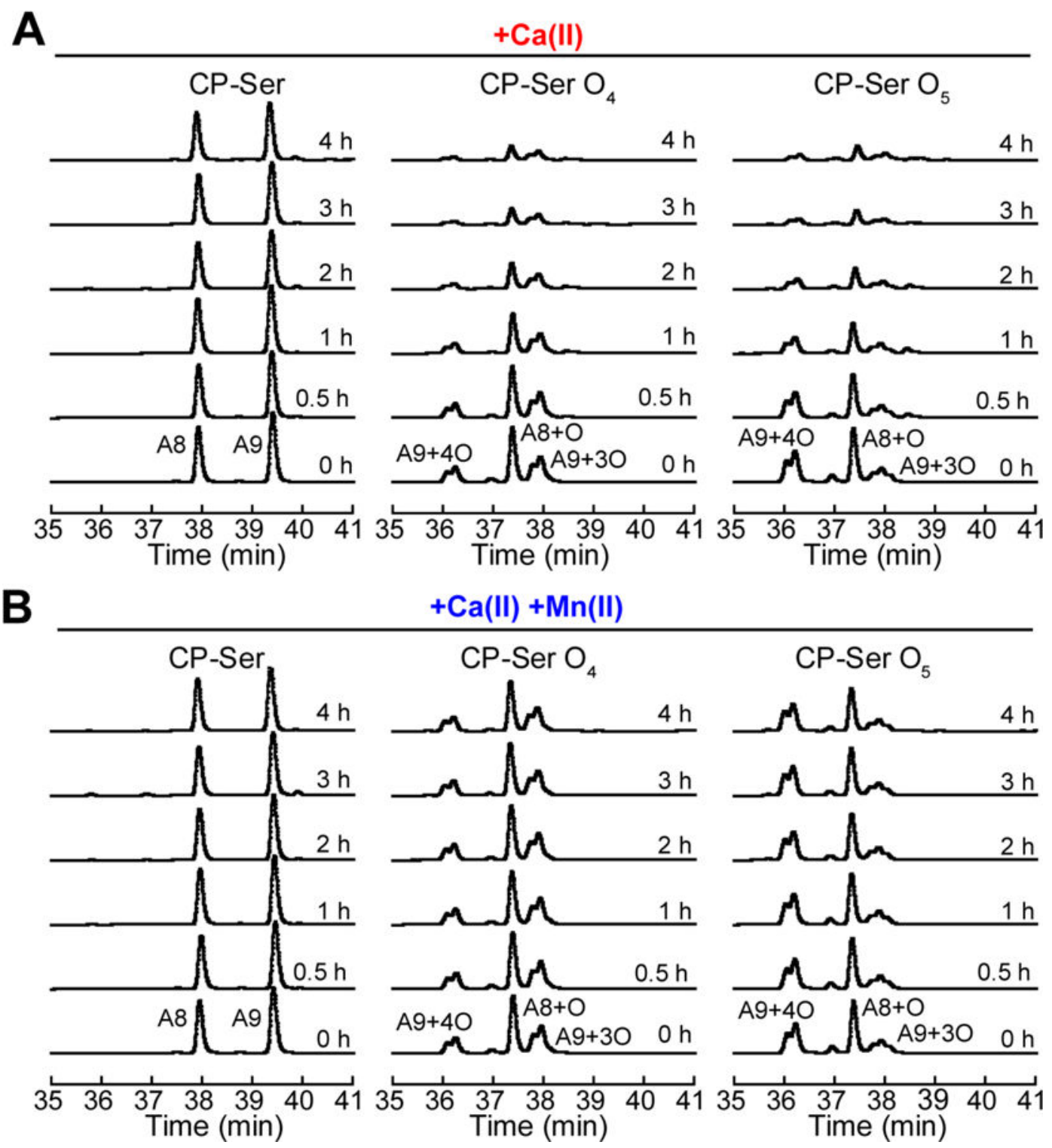

Figure 7.

Representative HPLC traces from trypsin $(0.45 \mu \mathrm{M})$ digestions of $30 \mu \mathrm{M}$ CP-Ser, CP-Ser $\mathrm{O}_{4}$, and CP-Ser $\mathrm{O}_{5}\left(75 \mathrm{mM}\right.$ HEPES, $100 \mathrm{mM} \mathrm{NaCl}, \mathrm{pH} 7.5,37^{\circ} \mathrm{C}$ ). (A) In the presence of $1.5 \mathrm{mM} \mathrm{Ca}(\mathrm{II})$. (B) In the presence of $1.5 \mathrm{mM} \mathrm{Ca}(\mathrm{II})$ and $30 \mu \mathrm{M} \mathrm{Mn}(\mathrm{II})$. 
A

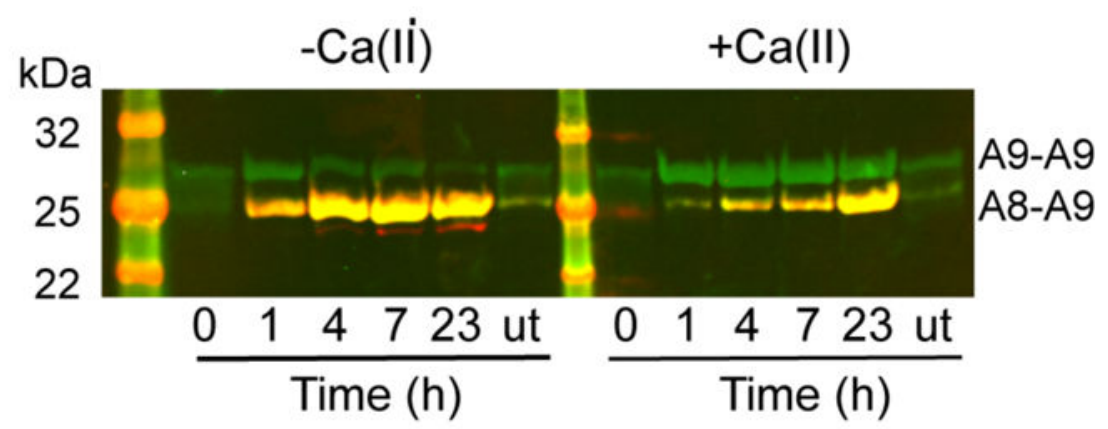

B

-TCEP
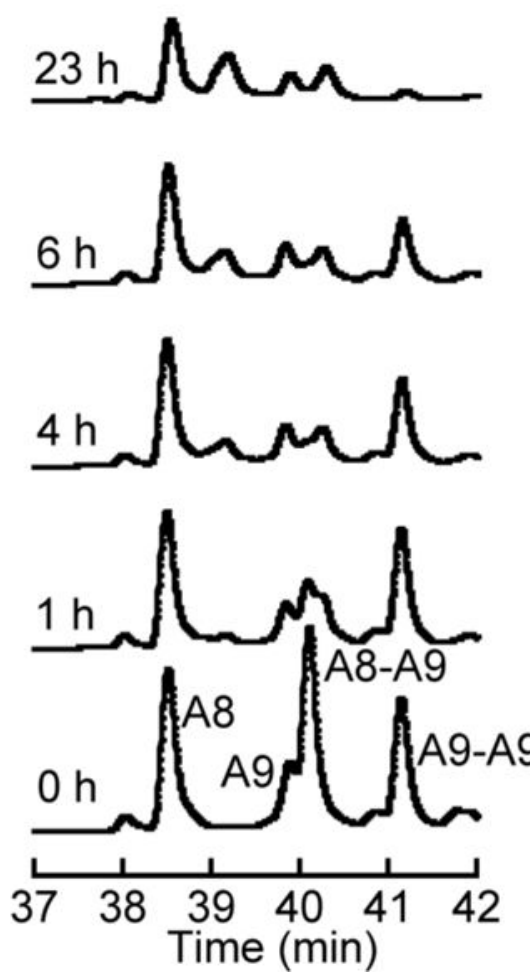

+ TCEP

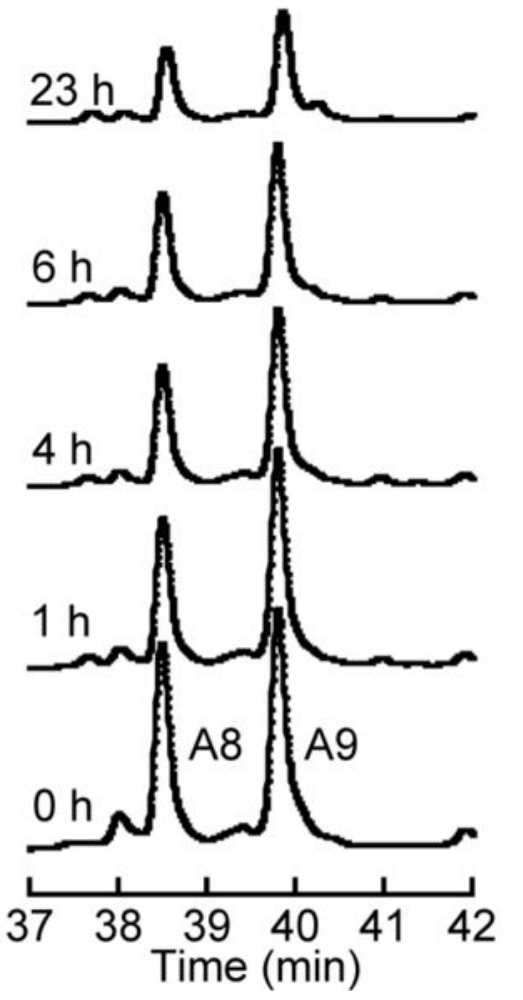

Figure 8.

Evaluation of disulfide-linked CP. The abbreviation u.t. stands for untreated. (A) A nonreducing western blot of $30 \mu \mathrm{M} \mathrm{CP}$ treated with $100 \mu \mathrm{M} \mathrm{H}_{2} \mathrm{O}_{2}$ at various points in time in the presence and absence of $1.5 \mathrm{mM} \mathrm{Ca(II)} \mathrm{(75} \mathrm{mM} \mathrm{HEPES,} 100 \mathrm{mM} \mathrm{NaCl}, \mathrm{pH} 7.5)$. S100A8 is red (mouse anti-S100A8), S100A9 is green (goat anti-S100A9), and yellow indicates both subunits. Representative HPLC chromatograms of $30 \mu \mathrm{M}$ disulfide-linked CP treated with $0.45 \mu \mathrm{M}$ trypsin in the presence of $1.5 \mathrm{mM} \mathrm{Ca}$ (II) $(75 \mathrm{mM}$ HEPES, $100 \mathrm{mM}$ $\mathrm{NaCl}, \mathrm{pH}$ 7.5). Samples were quenched in the absence (left panel) and presence (right panel) of TCEP. 


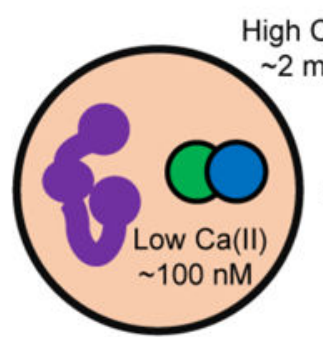

Neutrophil

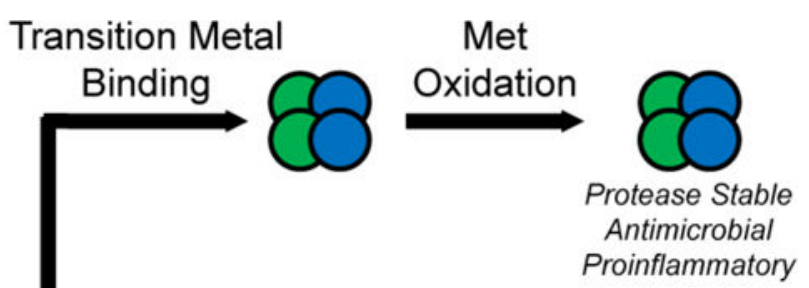

Met

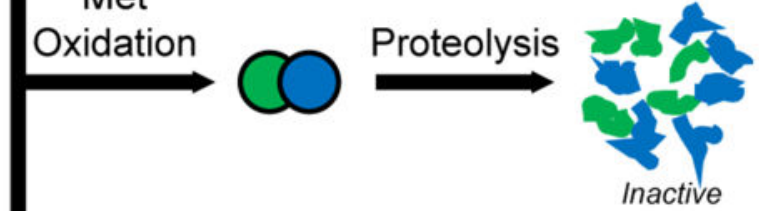

Proinflammatory

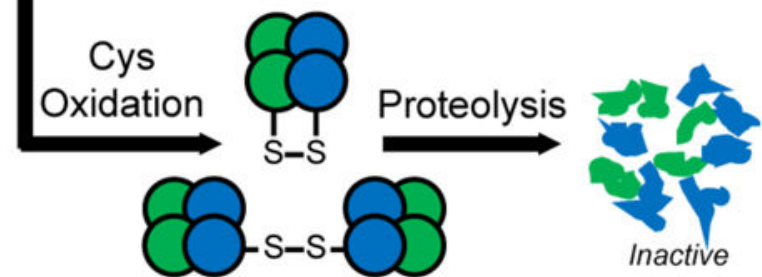

Figure 9.

Working model for the function and fate of extracellular $\mathrm{CP}$ considering the consequences of post-translational oxidation. Although not depicted, we expect that $\mathrm{CP}$ species containing disulfide bonds and MetO modifications without and with bound transition metal ions also exist. 
Table 1.

List of abbreviations used for proteins.

\begin{tabular}{|c|c|}
\hline Abbreviation & Construct $^{a}$ \\
\hline $\mathrm{CP}$ & S100A8/S100A9 \\
\hline $\mathrm{A} 9(\Delta \mathrm{M} 1)$ & S100A9 lacking Met1 \\
\hline A9( $\Delta \mathrm{M} 1-\mathrm{M} 5)$ & S100A9 lacking Met1, Thr2, Cys3, Lys4, and Met5 \\
\hline $\mathrm{A} 9(\mathrm{C} 3 \mathrm{~S})$ & S100A9(C3S) \\
\hline $\mathrm{A} 8+\mathrm{O}$ & S100A8 with 1 additional oxygen atom \\
\hline $\mathrm{A} 9+n \mathrm{O}$ & S100A9 with $n$ additional oxygen atoms \\
\hline CP-Ser & S100A8(C42S)/S100A9(C3S) \\
\hline${ }^{15} \mathrm{~N}-\mathrm{CP}-\mathrm{Ser}$ & {$\left[{ }^{15} \mathrm{~N}\right]-\mathrm{S} 100 \mathrm{~A} 8(\mathrm{C} 42 \mathrm{~S}) /\left[{ }^{15} \mathrm{~N}\right]-\mathrm{S} 100 \mathrm{~A} 9(\mathrm{C} 3 \mathrm{~S})$} \\
\hline${ }^{15} \mathrm{~N}-\mathrm{A} 8(\mathrm{C} 42 \mathrm{~S})$ & {$\left[{ }^{15} \mathrm{~N}\right]-\mathrm{S} 100 \mathrm{~A} 8(\mathrm{C} 42 \mathrm{~S})$} \\
\hline${ }^{15} \mathrm{~N}-\mathrm{A} 9(\mathrm{C} 3 \mathrm{~S})$ & {$\left[{ }^{15} \mathrm{~N}\right]-\mathrm{S} 100 \mathrm{~A} 9(\mathrm{C} 3 \mathrm{~S})$} \\
\hline M63A & S100A8(C42S)/S100A9(C3S)(M63A) \\
\hline M81A & S100A8(C42S)/S100A9(C3S)(M81A) \\
\hline M83A & S100A8(C42S)/S100A9(C3S)(M83A) \\
\hline $\mathrm{CP}-\mathrm{Ser} \mathrm{O}_{4}$ & CP-Ser with 4 oxidized Met residues $b$ \\
\hline CP-Ser $\mathrm{O}_{5}$ & CP-Ser with 5 oxidized Met residues $b$ \\
\hline MetO-disulfide-linked CP & $\mathrm{CP}$ with disulfide bonds and oxidized Met residues \\
\hline
\end{tabular}

